\title{
Política pública para a agricultura familiar: avaliação do Programa Paranaense "Fábrica do Agricultor"
}

\section{DÉCIO ESTEVÃO DO NASCIMENTO}

Universidade tecnológica Federal do Paraná

CAIO CESAR ZERBATO

Universidade tecnológica Federal do Paraná

CHRISTIAN LUIZ DA SILVA

Universidade tecnológica Federal do Paraná

MARTA CHAVES VASCONCELOS

Pontifícia Universidade Católica do Paraná

\section{Resumo}

No Estado do Paraná, em 1999 foi criado o programa Agroindústria Familiar "Fábrica do Agricultor"-PFA, com o objetivo de agregar valor aos produtos oriundos da agricultura familiar através da verticalização da produção pela agroindustrialização de pequeno porte. Assim, o objetivo geral deste estudo consistiu em avaliar o programa Agroindústria Familiar "Fábrica do Agricultor". A pesquisa foi desenvolvida de forma descritiva quanto à abordagem dos seus objetivos, com a utilização das técnicas de pesquisa bibliográfica, pesquisa documental e levantamento, com a utilização de entrevistas estruturadas. A política apresentou resultados diferenciados entre os objetivos propostos, sendo extremamente bem sucedida nos objetivos de inovação tecnológica, foco no mercado e apoio à agricultura familiar. Ficou evidenciado a relevância da agricultura familiar no estado paranaense e a significativa contribuição das políticas públicas para o fortalecimento da agricultura familiar.

Palavras-chave: Agroindústria Familiar. "Fábrica do Agricultor”. Agroindústrias. Políticas públicas.

Public policy for family farming: evaluation of the Program "Farmer's Factory" (Fábrica do Agricultor)

\section{Abstract}

In the state of Paraná, in 1999 the Family Agribusiness program "Factory Farmer" (PFA) was created with the objective of adding value to products from family farming through the vertical integration of production by small agro-industrialization. Thus, the aim of this study 

Agricultor"

was to evaluate the Family Agribusiness program "Factory Farmer". The research was conducted descriptively as to approach their goals with the use of bibliographic research techniques, document research and survey, using structured interviews. The policy presented different results between the proposed objectives, being extremely successful in technological innovation objectives, market focus and support for family farming. He highlighted the importance of family farming in Paraná state and the significant contribution of public policies to strengthen family farming.

Keywords: Family Agribusiness. family farming. "Factory Farmer". Agribusinesses, Agroindustries. Public Policies.

\section{Política pública para la agricultura familiar: evaluación del Programa Paranaense "Fábrica del Agricultor"}

\section{Resumen}

En el Estado de Paraná, en 1999 fue creado el programa Agroindustria Familiar "Fábrica del Agricultor" (PFA), con el objetivo de agregar valor a los productos oriundos de la agricultura familiar a través de la verticalización de la producción por la agroindustrialización de pequeño porte. Así, el objetivo general de este estudio consistió en evaluar el programa Agroindustria Familiar "Fábrica del Agricultor". La investigación fue desarrollada de forma descriptiva en cuanto al abordaje de sus objetivos, con la utilización de las técnicas de investigación bibliográfica, investigación documental y levantamiento, con la utilización de entrevistas estructuradas. La política presentó resultados diferenciados entre los objetivos propuestos, siendo extremadamente exitosa en los objetivos de innovación tecnológica, foco en el mercado y apoyo a la agricultura familiar. Se evidenció la relevancia de la agricultura familiar en el estado paranaense y la significativa contribución de las políticas públicas para el fortalecimiento de la agricultura familiar.

Palabras clave: Agroindustria Familiar. "Fábrica do Agricultor". Agroindustrias. Políticas públicas.

\section{Introdução}

O processo de modernização da agricultura brasileira fomentado pelo Estado não privilegiou todos os estratos de agricultores presentes no meio rural. Essa política agrícola atingiu o público alvo dos agricultores chamados de modernizáveis, detentores de extensas propriedades de terras e com a produção de gêneros agrícolas destinados ao mercado internacional (GRAZIANO DA SILVA, 1981).

Em 1996, houve a implantação do Programa Nacional de Fortalecimento da Agricultura Familiar-PRONAF, que se tornou a primeira demonstração de que o Estado estaria efetivamente direcionando suas ações para a concepção de políticas públicas para os agricultores familiares.

No Estado do Paraná, no ano de 1999, a partir dessa ênfase de que a agricultura familiar necessitava de políticas públicas especificas, o Governo do Estado do Paraná, com a coordenação da Secretaria de Estado da Agricultura e Abastecimento-Seab/PR e execução do Instituto Paranaense de Assistência Técnica e Extensão Rural-Emater/PR, criou o programa Agroindústria Familiar "Fábrica do Agricultor"-PFA. O intuito era de promover a agroindustrialização de pequeno porte na agricultura familiar, público prioritário do programa, transformando-os em 
produtos típicos ou diferenciados, permitindo a inserção desses agricultores no mercado e viabilizando os empreendimentos (SECRETARIA..., 2011).

A relevância do setor agropecuário compreende a participação em 7,61\% do Valor Adicionado Bruto-VAB do Produto Interno Bruto-PIB paranaense (IPARDES, 2012). Dentro dessa esfera, são 302.907 (trezentos e dois mil, novecentos e sete) estabelecimentos rurais em regime de agricultura familiar no estado paranaense, compreendendo $81,63 \%$ do total de estabelecimentos agropecuários. Esses estabelecimentos familiares ocupam $27,80 \%$ da área total e $69,85 \%$ do pessoal ocupado nas atividades agrícolas. A agricultura familiar ainda é responsável por aproximadamente $43 \%$ do Valor Bruto de Produção-VBP da agropecuária paranaense (PEREIRA; BAZOTTI, 2010).

Contudo, cabe avaliar o alinhamento da política pública e seus objetivos com os resultados no atendimento das demandas oriundas das agroindústrias familiares paranaenses. Para tanto, este artigo tem como objetivo avaliar o PFA considerando seus objetivos explícitos e seus resultados, de acordo com a percepção dos agentes envolvidos.

Nesse contexto, cabe destacar o importante papel que se atribui às políticas públicas para os agricultores familiares. Torna-se relevante a compreensão dos resultados das políticas para os cidadãos beneficiários dos programas. Avaliar os resultados do PFA consiste em evidenciar se efetivamente as ações propostas pelo Estado para este segmento estão de acordo com o planejado na implementação do programa.

Este artigo está organizado em 5 seções, incluindo esta introdução. A próxima seção relaciona campesinato e movimentos sociais: a agricultura familiar na busca por autonomia e os aspectos teóricos e metodológicos de políticas públicas. A terceira seção detalha a metodologia de pesquisa $A$ quarta seção apresenta os resultados da pesquisa e a quinta seção, as considerações finais.

\section{Campesinato e movimentos sociais: a agricultura familiar na busca por autonomia}

Articula-se, a partir de 1990, a definitiva integração da agricultura familiar no centro das ações governamentais por intermédio das políticas públicas para o fortalecimento desta estratégia de desenvolvimento rural no Estado brasileiro (ABRAMOVAY, 1997). As pressões dos movimentos sociais e os novos debates e concepções sobre a ruralidade legitimaram as ações afirmativas de políticas públicas voltadas para o desenvolvimento da agricultura familiar. Para tanto, a agricultura familiar alça ao patamar de "uma categoria social considerada específica e que necessitava de políticas públicas diferenciadas" (SCHNEIDER, 2003, p. 3-3).

A ação do Estado na afirmação e reconhecimento da importância socioeconômica da agricultura familiar foi expressa pela primeira política pública exclusiva de apoio ao segmento, o Programa Nacional de Fortalecimento da Agricultura Familiar (PRONAF), em 1996. Provendo a partir de então critérios para a determinação dos beneficiários do programa, abrangendo as questões de condição de posse dos estabelecimentos agropecuários e local de residência da família, limite máximo de renda monetária auferida no ano e originada na unidade rural e 
estabelecimento de quantidade de emprego de mão de obra assalariada na propriedade.

No âmbito de políticas públicas do Governo Federal, efetivamente a agricultura familiar passou a integrar as diretrizes estratégicas para 0 desenvolvimento rural. A partir da consolidação do Pronaf, foi criada em 1998 o Pronaf Agroindústria e, além disso, outras linhas de financiamento do programa surgiram para o apoio à agricultura familiar (SCHNEIDER; MATTEI; CAZELLA, 2009). Além das políticas públicas do governo federal, em diversos estados foram criados programas voltados para o desenvolvimento da agricultura familiar, principalmente nas estratégias de agroindustrialização dos produtos, considerados dentre estes o Estado do Paraná, com a criação do PFA em 1999 (WESZ JÚNIOR, 2009).

O PFA surgiu como uma estratégia para a manutenção da família rural no campo. Tal estratégia passa pela viabilidade dos estabelecimentos rurais por meio da agroindustrialização de pequeno porte de produtos alimentares, fomentando a geração de emprego e renda para os agricultores familiares. A agroindustrialização permite a criação de novos produtos e busca de novos mercados para a comercialização (SECRETARIA..., 2011).

Os objetivos ou premissas do programa estão agrupados em seis eixos principais: inovação tecnológica, foco no mercado, sustentabilidade, integração com as entidades, desenvolvimento regional e apoio à agricultura familiar. O PFA, em seu escopo busca atuar fortemente na adequação das unidades rurais aos processos de constituição e regularização dos produtos destinados à comercialização. Além disso, destacam-se as ações de identificação de mercados potenciais para a expansão das vendas e a profissionalização dos agricultores por intermédio de cursos de capacitação, relacionados desde os aspectos do processo produtivo como também a gestão dos estabelecimentos (SECRETARIA..., 2011).

\section{Aspectos teóricos e metodológicos de políticas públicas}

O surgimento de uma política pública específica para a agricultura familiar, oriunda de demandas sociais históricas, demonstrou a opção do Estado em planejar e fomentar as estratégias de desenvolvimento deste modelo de exploração agrícola, desencadeando a criação de diversos programas governamentais para o segmento. Nesse sentido, o conceito de política pública envolve as ações e decisões do Estado somadas a participação do conjunto dos demais atores sociais.

Simão et al. (2010) compreendem as políticas públicas como atividades contínuas da administração pública na observância dos objetivos e metas do planejamento estatal.

Heidemann (2009) faz referência às políticas públicas entendidas como "políticas de Estado", sendo aquelas que permanecem sem modificações ou com poucas alterações, transpassando os ciclos de administradores públicos. As políticas sociais, por sua vez, seriam caracterizadas por serem direcionadas a questões específicas de um segmento da sociedade. As políticas públicas podem ser compreendidas por meio de modelos conceituais de análise.

Dye (2009) descreve que os modelos conceituais permitem capturar elementos ou características das políticas implementadas, identificando, na prática, os pontos de convergência com as teorias descritas. 
A categoria de análise de policy cicle é entendida pelo desenvolvimento de um ciclo nas políticas públicas, separado em estágios e dotado de dinamismo. A participação de diversos atores sociais nos estágios do ciclo da política permite que os processos estejam inseridos em um ambiente de inter-relações entre os participantes e de estabelecimento de um fluxo de informações (SOUZA, 2006).

Frey (2000, p. 226) define as fases ou estágios de análise do ciclo da política pública em "percepção e definição de problemas, "agenda setting”, elaboração de programas e decisão, implementação de políticas e, finalmente, a avaliação de políticas e eventual correção".

Para Frey (2000), a fase de definição e percepção de problemas é o estágio em que efetivamente um determinado fato torna-se objeto de uma demanda social para a necessidade da promoção de uma política pública. Seguido pela "agenda setting" que confere o instante em que definitivamente a demanda social integra a agenda política e as discussões em torno dos grupos de interesse e demais participantes, definindo a concepção sobre a elaboração da política.

Oliveira (2006) prioriza a análise da etapa de implementação das políticas públicas. As políticas são decorrentes de um processo de planejamento, condicionando os resultados ao sucesso do estágio de implementação.

A avaliação das políticas públicas materializadas em programas governamentais está intimamente relacionada aos interesses dos formuladores policy-makers -, bem como dos demais gestores públicos. Como aspecto principal, ressaltam-se as questões que abordam a eficiência dos programas em atingirem os objetivos propostos, compreendendo a avaliação das atividades governamentais como direcionada para "o interesse mais imediato para realizar estudos e pesquisas de avaliação das atividades do governo estaria ligado a auferir os diversos resultados - esperados e não-esperados - alcançados pelos programas" (UNIVERSIDADE..., 1999, p. 132).

Nesse contexto, a avaliação das políticas públicas é indispensável para as medidas de desempenho da administração e para o fornecimento de informações e relatórios fidedignos que sustentem a tomada de decisão dos policy-makers. A avaliação das políticas compreende "a avaliação dos resultados de um programa em relação aos objetivos propostos" (ALA-HARJA; HELGASON, 2000, p. 8).

\section{Metodologia}

Trata-se de uma pesquisa qualitativa com abordagem predominantemente descritiva. Em termos de procedimentos técnicos, a pesquisa faz uso das técnicas de pesquisa bibliográfica, pesquisa documental e levantamento, com a utilização de entrevistas estruturadas (LAKATOS; MARCONI, 1992).

Para identificar a percepção dos agentes envolvidos no programa em relação aos resultados alcançados pelo mesmo, foi feito um levantamento, por meio de entrevistas estruturadas, com perguntas previamente estabelecidas em um roteiro. Segmentadas em perguntas fechadas - com alternativas fixas e de múltipla escolha - e perguntas abertas - de resposta livre do entrevistado, com uma amostra da população constituinte do público beneficiário do programa, policy-makers e representantes de algumas das entidades participantes da política. 

Agricultor"

No que tange à elaboração dos instrumentos de coleta de dados, a avaliação dos resultados do programa foi realizada em relação aos seus objetivos, definidos conforme o estabelecido no documento institucional diretivo do programa para o período de 2011 a 2014.

O público beneficiário, segundo o cadastro disponibilizado pelos coordenadores da política, abrange 1.320 (um mil trezentos e vinte) agroindústrias ativas no programa. Foram entrevistados 53 (cinquenta e três) produtores de agroindústrias familiares em eventos do PFA, realizados entre os dias 25 (vinte e cinco) a 29 (vinte e nove) de julho de 2012, na XIII Feira "Sabores do Paraná", em Curitiba, e entre os dias 12 (doze) a 13 (treze) de janeiro de 2013, na feira "Sabores do Paraná", em Guaratuba.

Além dos beneficiários do programa, foram realizadas entrevistas com 2 (dois) policy-makers da política nos dias 06 (seis) e 15 (quinze) de fevereiro de 2013. Da mesma forma, foi aplicado o roteiro de entrevistas com as entidades participantes (Apêndice C), desenvolvida as interrogações de 3 (membros) membros que desempenhem funções estratégicas na interação com o PFA em cada entidade, estabelecendo no total de 2 (duas) entidades participantes. As entrevistas com os membros das entidades participantes foram realizadas nos dias 17 (dezessete) e 22 (vinte e dois) de janeiro e 08 (oito) de fevereiro de 2013.

O Quadro 1 sintetiza os objetivos e conceitos abordados para a elaboração dos roteiros das entrevistas.

Quadro 1. Objetivos e conceitos abordados para a elaboração dos instrumentos de coleta de dados

\begin{tabular}{|c|c|c|}
\hline Entrevistado & Objetivo & Conceitos abordados \\
\hline Beneficiários & $\begin{array}{l}\text { Identificar os } \\
\text { resultados } \\
\text { decorrentes da } \\
\text { implementação } \\
\text { do PFA. }\end{array}$ & $\begin{array}{l}\text { Localização geográfica, perfil da agroindústria (condição de posse } \\
\text { e tamanho dos estabelecimentos, mão de obra e gênero, origem } \\
\text { dos produtos, matéria-prima, nível tecnológico, volume de } \\
\text { produção, destino dos resíduos produtivos, fontes de renda da } \\
\text { família) e os objetivos do PFA: inovação tecnológica, foco no } \\
\text { mercado, sustentabilidade, integração com as entidades, } \\
\text { desenvolvimento regional e apoio à agricultura familiar. }\end{array}$ \\
\hline Policy-makers & $\begin{array}{l}\text { Identificar o ciclo } \\
\text { de vida do } \\
\text { programa e os } \\
\text { resultados } \\
\text { decorrentes da } \\
\text { implementação } \\
\text { do PFA. }\end{array}$ & $\begin{array}{l}\text { Perfil profissional do policy-maker (formação, titulação, } \\
\text { experiências profissionais, tempo de trabalho e posições } \\
\text { hierárquicas ocupadas na estrutura do programa), ciclo de vida do } \\
\text { programa (policy analysis), objetivos da política, recursos } \\
\text { disponíveis, desafios e oportunidades, crédito rural, integração } \\
\text { com as entidades, viabilidade das agroindústrias, monitoramento } \\
\text { e avaliação do programa, nível de satisfação quanto aos } \\
\text { resultados e expectativas sobre a política pública. }\end{array}$ \\
\hline $\begin{array}{c}\text { Entidades } \\
\text { Participantes }\end{array}$ & $\begin{array}{l}\text { Identificar o ciclo } \\
\text { de vida do } \\
\text { programa e os } \\
\text { resultados } \\
\text { decorrentes da } \\
\text { implementação } \\
\text { do PFA. }\end{array}$ & $\begin{array}{l}\text { Perfil profissional do entrevistado (formação, titulação, } \\
\text { experiências profissionais, tempo de trabalho e posições } \\
\text { hierárquicas ocupadas na estrutura da organização), ingresso da } \\
\text { entidade no programa, demandas e procedimentos de } \\
\text { atendimento, resultados para a organização, objetivos e metas, } \\
\text { visão dos resultados do programa, ações de integração com as } \\
\text { entidades participantes, desafios e oportunidades, nível de } \\
\text { satisfação quanto aos resultados e expectativas sobre a política } \\
\text { pública. }\end{array}$ \\
\hline
\end{tabular}

Fonte: Autoria própria. 
A elaboração do roteiro das entrevistas individuais com as agroindústrias familiares beneficiárias do Programa buscou identificar o perfil desses beneficiários - principalmente relacionado às questões de localização do empreendimento, tempo de existência, tamanho da propriedade, mão de obra utilizada, produção permitindo um diagnóstico da realidade destas agroindústrias.

$\mathrm{Na}$ sequência do questionário, foram abordadas questões relacionadas aos objetivos traçados no escopo do PFA e a avaliação dos beneficiários acerca do programa.

$O$ roteiro de entrevistas com os policy-makers tiveram o intuito de compreender, a partir da visão dos formuladores, implementadores e decisores, as etapas do ciclo de vida do Programa, como ele se articula com as demais entidades participantes nas diversas atividades da política e principalmente os resultados atingidos decorres da implementação do PFA. Da mesma forma, será procedido quanto aos objetivos das entrevistas com as entidades participantes.

Na sequência, foi realizada a etapa analítica do trabalho, com o tratamento dos dados e a identificação dos resultados alcançados decorrentes da implementação do PFA, classificando-os conforme a análise do nível de aderência desses resultados aos objetivos propostos pela política.

\section{Análise dos resultados}

A partir das informações oriundas das entrevistas com os policy-makers e as entidades participantes, foram mapeadas as ações e elencadas as etapas do ciclo de vida do PFA. A conjunção dos levantamentos do público-alvo beneficiário, policy-makers e entidades participantes demonstraram os resultados alcançados pelo programa decorrentes da sua implementação, classificando-os conforme a análise do nível de aderência desses resultados aos objetivos propostos pela política. O Quadro 2 sintetiza os níveis e os critérios de análise utilizados. 
Política pública para a agricultura familiar: avaliação do Programa Paranaense “Fábrica do Agricultor"

\section{Quadro 2. Nível de aderência dos resultados apresentados aos objetivos propostos}

no PFA

\begin{tabular}{|c|c|c|c|}
\hline Objetivo do PFA & $\begin{array}{l}\text { Quantidade de } \\
\text { itens avaliados } \\
\text { em cada objetivo }\end{array}$ & $\begin{array}{c}\text { Nível de aderência } \\
\text { dos resultados aos } \\
\text { objetivos do } \\
\text { programa }\end{array}$ & Critérios de análise \\
\hline \multirow{3}{*}{$\begin{array}{l}\text { Inovação } \\
\text { tecnológica }\end{array}$} & \multirow{3}{*}{4} & Alto & $\begin{array}{l}\text { Percepção positiva da maioria dos beneficiários entrevistados } \\
\text { em relação a pelo menos } 3 \text { (três) itens avaliados. }\end{array}$ \\
\hline & & Médio & $\begin{array}{l}\text { Percepção positiva da maioria dos beneficiários entrevistados } \\
\text { em relação a pelo menos } 2 \text { (dois) itens avaliados. }\end{array}$ \\
\hline & & Baixo & $\begin{array}{l}\text { Percepção positiva da maioria dos beneficiários entrevistados } \\
\text { em relação a pelo menos } 1 \text { (um) ou em nenhum dos itens } \\
\text { avaliados. }\end{array}$ \\
\hline \multirow{3}{*}{ Foco no mercado } & \multirow{3}{*}{6} & Alto & $\begin{array}{l}\text { Percepção positiva da maioria dos beneficiários entrevistados } \\
\text { em relação a pelo menos } 5 \text { (cinco) itens avaliados. }\end{array}$ \\
\hline & & Médio & $\begin{array}{l}\text { Percepção positiva da maioria dos beneficiários entrevistados } \\
\text { em relação a pelo menos } 4 \text { (quatro) itens avaliados. }\end{array}$ \\
\hline & & Baixo & $\begin{array}{l}\text { Percepção positiva da maioria dos beneficiários entrevistados } \\
\text { em relação a pelo menos } 3 \text { (três) ou em nenhum dos itens } \\
\text { avaliados. }\end{array}$ \\
\hline \multirow{3}{*}{ Sustentabilidade } & \multirow{3}{*}{4} & Alto & $\begin{array}{l}\text { Percepção positiva da maioria dos beneficiários entrevistados } \\
\text { em relação a pelo menos } 3 \text { (três) itens avaliados. }\end{array}$ \\
\hline & & Médio & $\begin{array}{l}\text { Percepção positiva da maioria dos beneficiários entrevistados } \\
\text { em relação a pelo menos } 2 \text { (dois) itens avaliados. }\end{array}$ \\
\hline & & Baixo & $\begin{array}{l}\text { Percepção positiva da maioria dos beneficiários entrevistados } \\
\text { em relação a pelo menos } 1 \text { (um) ou em nenhum dos itens } \\
\text { avaliados. }\end{array}$ \\
\hline \multirow{3}{*}{$\begin{array}{l}\text { Integração com } \\
\text { as entidades }\end{array}$} & \multirow{3}{*}{4} & Alto & $\begin{array}{l}\text { Percepção positiva da maioria dos beneficiários entrevistados } \\
\text { em relação a pelo menos } 3 \text { (três) itens avaliados. }\end{array}$ \\
\hline & & Médio & $\begin{array}{l}\text { Percepção positiva da maioria dos beneficiários entrevistados } \\
\text { em relação a pelo menos } 2 \text { (dois) itens avaliados. }\end{array}$ \\
\hline & & Baixo & $\begin{array}{l}\text { Percepção positiva da maioria dos beneficiários entrevistados } \\
\text { em relação a pelo menos } 1 \text { (um) ou em nenhum dos itens } \\
\text { avaliados. }\end{array}$ \\
\hline \multirow{3}{*}{$\begin{array}{l}\text { Desenvolvimento } \\
\text { regional }\end{array}$} & \multirow{3}{*}{4} & Alto & $\begin{array}{l}\text { Percepção positiva da maioria dos beneficiários entrevistados } \\
\text { em relação a pelo menos } 3 \text { (três) itens avaliados. }\end{array}$ \\
\hline & & Médio & $\begin{array}{l}\text { Percepção positiva da maioria dos beneficiários entrevistados } \\
\text { em relação a pelo menos } 2 \text { (dois) itens avaliados. }\end{array}$ \\
\hline & & Baixo & $\begin{array}{l}\text { Percepção positiva da maioria dos beneficiários entrevistados } \\
\text { em relação a pelo menos } 1 \text { (um) ou em nenhum dos itens } \\
\text { avaliados. }\end{array}$ \\
\hline \multirow{3}{*}{$\begin{array}{l}\text { Apoio à } \\
\text { agricultura } \\
\text { familiar }\end{array}$} & \multirow{3}{*}{4} & Alto & $\begin{array}{l}\text { Percepção positiva da maioria dos beneficiários entrevistados } \\
\text { em relação a pelo menos } 3 \text { (três) itens avaliados. }\end{array}$ \\
\hline & & Médio & $\begin{array}{l}\text { Percepção positiva da maioria dos beneficiários entrevistados } \\
\text { em relação a pelo menos } 2 \text { (dois) itens avaliados. }\end{array}$ \\
\hline & & Baixo & $\begin{array}{l}\text { Percepção positiva da maioria dos beneficiários entrevistados } \\
\text { em relação a pelo menos } 1 \text { (um) ou em nenhum dos itens } \\
\text { avaliados. }\end{array}$ \\
\hline
\end{tabular}

Fonte: Autoria própria

Nota: Os itens avaliados em cada objetivo do programa estão dispostos conforme referenciados no Quadro 1. 
Décio Estevão do Nascimento, Caio Cesar Zerbato, Christian Luiz da Silva, Marta Chaves Vasconcelos

\subsection{Caracterização e dimensionamento}

Nas décadas de 1980 e 1990, diversas políticas públicas para a pequena produção familiar foram desenvolvidas concomitantemente no estado paranaense. Implementa-se em 1995 o programa de Vilas Rurais, posteriormente, em 1998, adicionado ao projeto Paraná 12 Meses, tendo como objetivo o combate a pobreza no meio rural, como foco nas famílias rurais e nos trabalhadores do campo. Em 1999 a implementação do PFA, demonstrou a efetiva importância das pequenas propriedades na questão agrária no Estado do Paraná (ESSER et al., 2006; GODOY, 2006).

O Estado do Paraná está dividido territorialmente pelo critério de mesorregiões geográficas do Instituto Brasileiro de Geografia e Estatística-IBGE. As dez mesorregiões paranaenses são: Centro Ocidental Paranaense, Centro Oriental Paranaense, Centro-Sul Paranaense, Metropolitana de Curitiba, Noroeste Paranaense, Norte Central Paranaense, Norte Pioneiro Paranaense, Oeste Paranaense, Sudeste Paranaense e Sudoeste Paranaense. A partir da análise dos dados de Censo Demográfico 2010 do IBGE, a mesorregião Metropolitana de Curitiba apresenta-se como a mais populosa do estado paranaense e com o maior Grau de Urbanização, com índice de 91, 57\%. A mesorregião Sudeste Paranaense tem o menor índice de urbanização, sendo constatado que entre os 21 (vinte e um) municípios da mesorregião, 16 (dezesseis) deles são de pequeno porte com menos de 20 (vinte) mil habitantes e nenhum possui mais de 100 (cem) mil habitantes.

Segundo o Instituto Paranaense de Desenvolvimento Econômico e SocialIpardes (2004), a mesorregião Sudoeste é o tradicional território da agricultura familiar no estado paranaense. Com significativas transformações da base produtiva nas últimas décadas, caracterizada por ocupações recentes do território e pelo relevo acidentado, dificultando o incremento de mecanização no processo produtivo no meio rural. A mesorregião Sudeste, menos urbanizada do estado, caracteriza-se também como importante reduto da agricultura familiar, com antigas ocupações de núcleos coloniais de imigrantes e produção de alimentos básicos em pequenas propriedades. A Figura 1 detalha as Mesorregiões Geográficas do Estado do Paraná. 
Política pública para a agricultura familiar: avaliação do Programa Paranaense "Fábrica do Agricultor"

Figura 1. Mapa do Estado do Paraná, segundo a subdivisão em Mesorregiões Geográficas

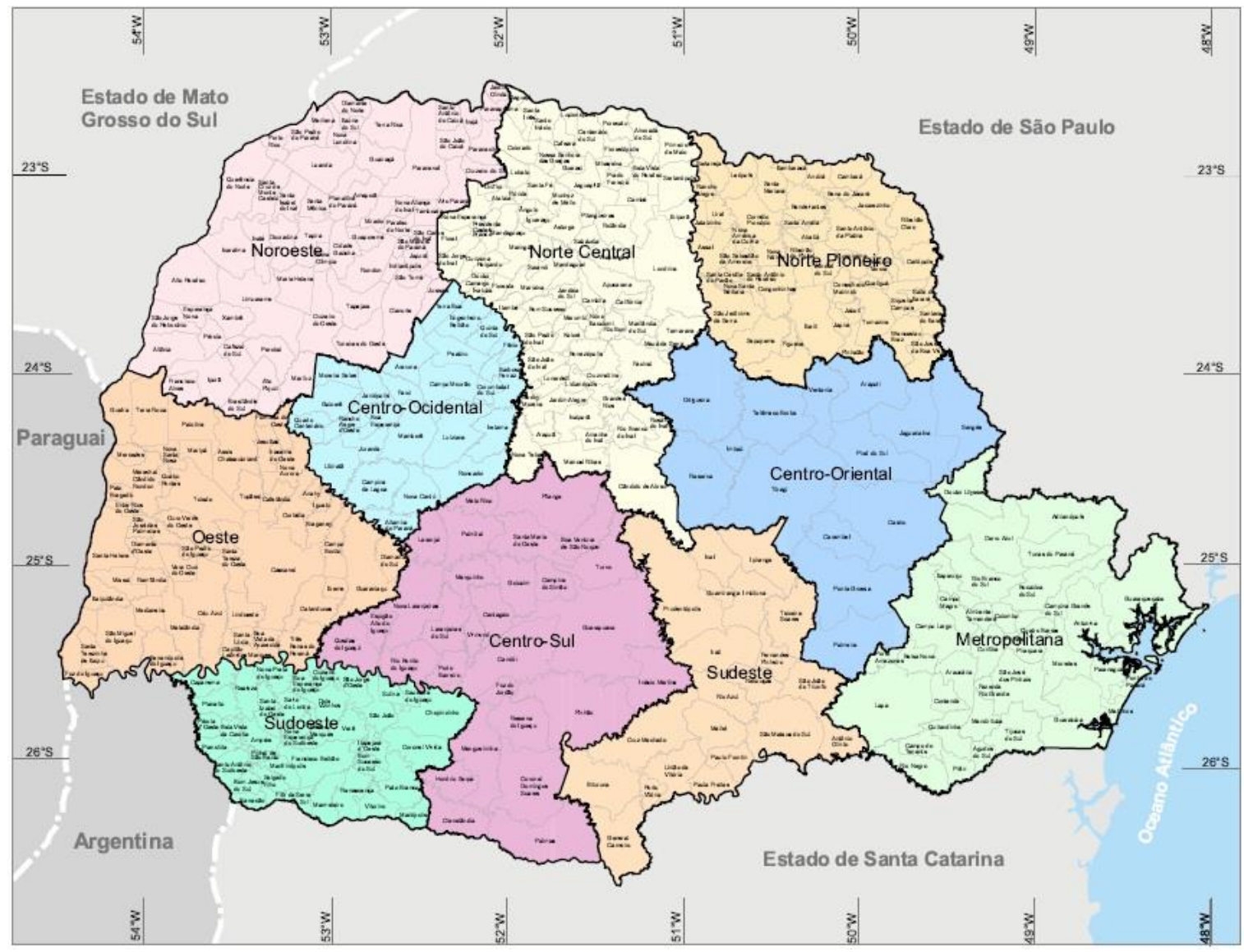

Fonte: IBGE; Base Cartográfica do ITCG (2010).

Além das mesorregiões Sudeste e Sudoeste como tradicionais redutos da agricultura familiar, os dados do Censo Agropecuário $2006^{1}$ do IBGE revelam a ampla distribuição das unidades familiares de produção no território paranaense (Tabela 1).
A delimitação do conceito de agricultura familiar no Censo Agropecuário 2006 está disposta conforme a Lei $\mathrm{n}^{\circ}$ 11.326 , de 24 julho de 2006, que estabeleceu as diretrizes para a formulação da Política Nacional da Agricultura Familiare Empreendimentos Familiares Rurais, institucionalizando o marco legal da agricultura familiar (INSTITUTO..., 2009). 
Décio Estevão do Nascimento, Caio Cesar Zerbato, Christian Luiz da Silva, Marta Chaves Vasconcelos

Tabela 1. Estabelecimento e área da agricultura familiar e não familiar, segundo as Mesorregiões - Paraná - 2006

\begin{tabular}{l|cc|cc}
\hline \multirow{2}{*}{ Mesorregiões } & \multicolumn{2}{c|}{ Agricultura Familiar } & \multicolumn{2}{c}{ Não Familiar } \\
\cline { 2 - 5 } & Estabelecimentos & Área (ha) & Estabelecimentos & Área (ha) \\
\hline & & & & \\
Centro Ocidental Paranaense & 16.770 & 274.779 & 4.540 & 836.397 \\
Centro Oriental Paranaense & 14.625 & 187.392 & 4.549 & 1.472 .161 \\
Centro-Sul Paranaense & 33.588 & 513.993 & 7.780 & 1.413 .708 \\
Metropolitana de Curitiba & 25.889 & 247.889 & 4.569 & 568.152 \\
Noroeste Paranaense & 29.323 & 454.243 & 8.400 & 1.768 .791 \\
Norte Central Paranaense & 41.407 & 553.673 & 12.865 & 1.836 .732 \\
Norte Pioneiro Paranaense & 23.356 & 308.934 & 6.305 & 1.034 .953 \\
Oeste Paranaense & 43.752 & 646.986 & 9.464 & 1.069 .601 \\
Sudeste Paranaense & 34.665 & 495.359 & 4.725 & 632.843 \\
Sudoeste Paranaense & 39.532 & 566.635 & 4.947 & 403.316 \\
& & & & 11.036 .652 \\
\hline
\end{tabular}

Fonte: IBGE - Censo Agropecuário (2009).

A mesorregião Oeste apresenta o maior número de estabelecimentos e a maior área empregada na agricultura familiar. Segundo o Ipardes (2004a), a mesorregião Oeste possui área com cerca de $75 \%$ do solo com característica boa e regular para a agricultura, destacando um excelente nível de incremento tecnológico nos processos produtivos.

A agricultura familiar possui mais de 302 (trezentos e dois) mil estabelecimentos agropecuários, representando $81,63 \%$ do total de estabelecimentos no estado. Em contraponto, a agricultura não familiar com 18,37\% dos estabelecimentos, ocupa $72,20 \%$ da área utilizada agropecuária, caracterizando este modelo produtivo como pautado na produção em unidades de grande extensão territorial.

Em relação à questão de gênero nas atividades agrícolas, as mulheres são $35,34 \%$ das pessoas ocupadas na agricultura familiar, frente ao número de $25,13 \%$ no segmento não familiar.

Nesse aspecto referente ao contingente de pessoas ocupadas nas atividades agropecuárias no segmento familiar, grande parte desta conjuntura é influenciada pela condição do produtor em relação às terras. Na agricultura familiar, os produtores que se declaram proprietários estão em cerca de $80,70 \%$ dos estabelecimentos, sendo para a agricultura não familiar em torno de $19,30 \%$ (INSTITUTO..., 2009). A expressiva quantidade de agricultores familiares declarados como proprietários dos estabelecimentos revelam a família como concomitantemente proprietária dos meios de produção, fornecedora de mão de obra no processo produtivo e gestora das unidades rurais.

A multifuncionalidade dos espaços rurais e a dinâmica agrícola nas unidades produtivas revelam em muitas unidades rurais a presença da pluriatividade. Segundo O IBGE (2009), as unidades rurais em que os produtores declararam a pluriatividade fora dos estabelecimentos compreendem $30,90 \%$ dos unidades agropecuárias paranaenses. 
Política pública para a agricultura familiar: avaliação do Programa Paranaense "Fábrica do Agricultor"

A partir dessa análise, compreende-se a relevância da promoção da agricultura familiar no estado da paranaense com vistas à eficiência do sistema agroalimentar (INSTITUTO..., 2007; MALUF, 2004).

\subsection{O Programa Agroindústria Familiar "Fábrica do Agricultor"}

Neste item, será apresentado o programa Agroindústria Familiar "Fábrica do Agricultor", com a utilização de pesquisa descritiva para a obtenção de maior familiaridade com o programa, realizada por meio de entrevistas com os policymakers e as entidades participantes. Tal levantamento foi utilizado para a identificação do ciclo de vida da política pública, permeando todas as suas etapas.

\subsubsection{Percepção, definição de problemas e agenda setting}

O primeiro estágio do policy cycle do PFA foi decorrente da conjuntura da dinâmica agrícola que se encontrava a agricultura paranaense. No Estado do Paraná, os incentivos para os processos de agroindustrialização se iniciaram na década de 1980, com a integração dos produtores de commodities agrícolas e de produtos de origem animal aos complexos agroindustriais. A partir desta experiência, desenvolveram-se as concepções de promoção de um programa de agroindustrialização de pequeno porte.

A estratégia de elaboração de um programa de verticalização da produção nas pequenas propriedades integrou a agenda política pelo interesse em viabilizar os pequenos produtores. Considerando o interesse da administração pública e dos demais atores sociais, foi estabelecido pelos envolvidos no processo o ambiente de discussões necessário para a elaboração do programa. (ENTREVISTADO PM1).

Além disso, segundo o Entrevistado PM2, a Emater/PR em toda a sua história, priorizou a inovação na agropecuária paranaense, buscando estar à frente das novas tendências.

\subsubsection{Elaboração do Programa e decisões}

A etapa de elaboração da proposta do programa de governo teve a participação inicial dos técnicos da Seab/PR e da Emater/PR, mas também contou com inspirações em outras políticas públicas do gênero (ENTREVISTADO PM1).

Após discussões preliminares sobre o escopo do programa e os pontos de atuação, foram criados um comitê central estadual e comitês regionais nos núcleos da Seab/PR, compostos por equipes multidisciplinares. Esses profissionais abordaram o levantamento das leis, portarias e resoluções acerca da produção e comercialização de produtos alimentícios. Em decorrência deste grupo de trabalho, foi realizado, em 1998, o primeiro seminário sobre agroindústria, abordando a temática da regularização das unidades - sanitária, ambiental e jurídica.

A elaboração da proposta do PFA esteve orientada para a execução dos parâmetros traçados para a política agrícola paranaense, centrada nos eixos: sanidade agropecuária, profissionalização dos agricultores e agregação de valor. 
Décio Estevão do Nascimento, Caio Cesar Zerbato, Christian Luiz da Silva, Marta Chaves Vasconcelos

\subsubsection{Implementação, avaliação e correção da política}

Desde o início, a implementação do PFA ocorreu em todas as regiões do Estado do Paraná. Segundo o Entrevistado PM2, desde o lançamento do programa, a demanda dos agricultores para participarem da política foi intensa, iniciando um processo de seleção e cadastramento dos beneficiários, que desde a implementação do programa atingiu 4.000 (quatro mil) beneficiários.

As estratégias de atuação do programa, consolidadas nas diretrizes básicas da política, estiveram de acordo com os objetivos da política agrícola paranaense voltada para os agricultores familiares. Assim, o PFA foi implementado com o foco de atuação em três principais frentes de trabalho: o "apoio à legalização das agroindústrias, capacitação dos agricultores e acesso aos mercados" (WESZ JUNIOR, 2009, p. 42). A estratégia operacional das atividades do programa foi pautada na subdivisão em quatro componentes, sendo eles: tecnologia, "KitAgilidade", incentivos, marketing, mercado e comercialização.

No componente tecnologia, a profissionalização dos agricultores foi uma das frentes de trabalho mais importantes no período de implementação do programa. Apenas no ano de 2000 foram oferecidos 205 (duzentos e cinco) cursos de capacitação e profissionalizantes aos produtores, dentre eles: cursos de embutidos, defumados, massa fina, derivados lácteos, picles, molhos, temperos, processamento mínimo de hortaliças, frutas desidratadas e outros (SECRETARIA..., 2010).

Na sequência de componentes da estratégia operacional do PFA, o "KitAgilidade" é a atividade desenvolvida para o objetivo de normatização, regulamentação e fiscalização das agroindústrias inscritas no programa (SECRETARIA..., 1999). A regularização dos empreendimentos dos pequenos agricultores foi um dos maiores desafios encontrados nas discussões sobre a elaboração do programa, haja vista a inúmera quantidade encontrada de empreendimentos que atuavam na ilegalidade durante o levantamento preliminar realizado pelos técnicos da Seab/PR e da Emater/PR.

Segundo o Entrevistado PM1, as estratégias de marketing, mercado e comercialização receberam uma atenção especial do programa. A destinação de recursos para essas atividades se deve ao fato que tais componentes se situam fora das atividades agrícolas, sendo necessário que os agricultores recebam maior apoio nestes itens que tenham menos familiaridade.

O marketing institucional do PFA esteve centrado em fortalecer a marca do programa, visando proporcionar credibilidade aos consumidores em consumirem produtos oriundos de agroindústrias participantes do programa (SECRETARIA..., 1999). Segundo a Seab (2010), em 2000, foi criado o Selo do Programa "Fábrica do Agricultor" e uma família de rótulos do programa para cada produto.

A estratégia de marketing e mercado esteve estreitamente interligada com a de comercialização na fase de implementação da política. Além da feira de Curitiba são realizadas anualmente as feiras do Litoral Paranaense e de Foz do Iguaçu.

O programa buscou, com a criação das feiras, a aproximação dos produtores com os consumidores finais, fortalecendo a identificação da marca da agroindústria. Além disso, foram fomentados outros canais de comercialização no âmbito do programa, como o convênio celebrado em 2003 com a Associação Paranaense de 
Política pública para a agricultura familiar: avaliação do Programa Paranaense "Fábrica do Agricultor"

Supermercados-APRAS, para a instalação de gôndolas nos supermercados paranaenses identificadas com o logotipo do PFA, fidelizando os consumidores aos produtos das agroindústrias participantes do programa.

As etapas de avaliação e correção da política abordaram questões conjunturais do programa, com a modificação de objetivos a serem atingidos e o aprimoramento do público alvo do PFA, sem a apresentação de alterações significativas na estrutura ou nas premissas básicas. Após a implementação do programa, foram realizados diversos fóruns, seminários e encontros para a avaliação da política nas diversas regiões do estado (SECRETARIA..., 2010).

O Quadro 3 elenca os objetivos da política, segundo os anos e conforme a ordem disposta nos documentos institucionais do PFA.

Quadro 3. Objetivos do PFA, segundo os anos - 1999- 2011

\begin{tabular}{|l|c|c|}
\hline \multirow{4}{*}{ Objetivos do programa } & 1999 & 2011 \\
\cline { 2 - 3 } & Integração ao mercado & Inovação tecnológica \\
\cline { 2 - 3 } & Gestão & Foco no mercado \\
\cline { 2 - 3 } & Qualidade & Sustentabilidade \\
\cline { 2 - 3 } & Tecnologia & Integração com as entidades \\
\cline { 2 - 3 } & Estímulos & Desenvolvimento regional \\
\cline { 2 - 3 } & Parceria institucional & Apoio à agricultura familiar \\
\hline
\end{tabular}

Fonte: SEAB (1999); SEAB (2010)

Nota: autoria própria

As modificações em alguns objetivos do programa refletem principalmente a visão dos formuladores da política de que as agroindústrias paranaenses atingiram outro estágio de desenvolvimento.

Com o desenvolvimento da política e das atividades agroindustriais de pequeno porte no estado, os objetivos da política foram modificados. As principais modificações estiveram centradas na inclusão dos objetivos de sustentabilidade, desenvolvimento regional e apoio à agricultura familiar (SECRETARIA..., 1999; SECRETARIA..., 2011).

A partir desta análise, o programa institucionalizou e definiu a agricultura familiar como o público prioritário do PFA.

\subsection{Identificação dos Resultados do Programa}

Para um melhor entendimento, a identificação dos resultados do programa foi dividida em três momentos. No primeiro, foi apresentado um diagnóstico da realidade das agroindústrias familiares e, na sequência, a percepção dos beneficiários, policy-makers e das entidades participantes sobre os resultados do PFA. 
Décio Estevão do Nascimento, Caio Cesar Zerbato, Christian Luiz da Silva, Marta Chaves Vasconcelos

\subsubsection{Diagnóstico da realidade das agroindústrias familiares}

Dentre as 1.320 (um mil trezentos e vinte) agroindústrias ativas no programa, participaram do estudo 53 (cinquenta e três), com a representação conforme demonstrado na Tabela 2.

Tabela 2. Distribuição de frequência das agroindústrias familiares no Estado do Paraná, segundo as mesorregiões

\begin{tabular}{lcc}
\hline \multicolumn{1}{c}{ Mesorregiões } & \multicolumn{2}{c}{ Agroindústrias familiares } \\
& Frequência & $\%$ \\
\hline Centro-Ocidental Paranaense & 6 & $11,32 \%$ \\
Centro-Oriental Paranaense & 3 & $5,66 \%$ \\
Centro-Sul Paranaense & 0 & $0,00 \%$ \\
Metropolitana de Curitiba & 12 & $22,64 \%$ \\
Noroeste Paranaense & 1 & $1,89 \%$ \\
Norte Central Paranaense & 9 & $16,98 \%$ \\
Norte Pioneiro Paranaense & 9 & $16,98 \%$ \\
Oeste Paranaense & 7 & $13,21 \%$ \\
Sudeste Paranaense & 3 & $5,66 \%$ \\
Sudoeste Paranaense & 3 & $5,66 \%$ \\
TOTAL & 53 & 100 \\
\hline
\end{tabular}

Fonte: Autoria própria.

Verificou-se, pela frequência apresentada na Tabela 2, a predominância das mesorregiões Metropolitana de Curitiba, Norte Central e Norte Pioneiro. A mesorregião Metropolitana de Curitiba apresentou um substancial contingente de agroindústrias. No entanto, cabe evidenciar que a mesorregião detém a segunda menor área ocupada dentre as mesorregiões paranaenses na agricultura familiar (INSTITUTO..., 2009).

O grande destaque da região é a produção de hortaliças, que necessitam de uma área menor de lavoura comparada a outras culturas. Os processos de agroindustrialização, dotados de técnicas mais avançadas e com vistas à comercialização dos produtos, está assentada no Município de Morretes, localidade historicamente produtora de produtos típicos e diferenciados (INSTITUTO..., 2004C).

A mesorregião Norte Central, que apresentou 16,98\% das agroindústrias familiares participantes do estudo, segundo o IBGE (2009), tem o segundo maior número de estabelecimentos da agricultura familiar no Estado do Paraná, com grande ocupação de lavouras temporárias e pastagens, sendo tradicional produtora de soja e milho. No segmento familiar, destacam-se os recentes movimentos de articulação da agroindústria e a produção de fruticultura (INSTITUTO..., 2004d). Já a mesorregião do Norte Pioneiro, segundo o Ipardes (2004e), é caracterizada por grandes propriedades, com ocupações de lavouras temporárias - principalmente soja e trigo.

Em relação às questões de enquadramento e tratamento tributário, os resultados apresentaram as mesmas frequências. Não houve casos em que as agroindústrias familiares detenham a personalidade jurídica, mas com algum membro da família enquadrado como produtor rural pessoa física, beneficiando-se 
Política pública para a agricultura familiar: avaliação do Programa Paranaense "Fábrica do Agricultor"

do tratamento tributário diferenciado e das linhas de crédito disponíveis para os agricultores familiares individuais, caracterizando que em um mesmo núcleo familiar exista a comercialização no enquadramento de pessoa física e também como personalidade jurídica.

No que tange às atividades cooperativistas, entre os participantes do estudo, 47,17\% dos beneficiários do PFA declaram estar vinculados a alguma cooperativa ou associação.

O tempo de existência das agroindústrias evidencia que $35,85 \%$ dos empreendimentos possuem entre 7 (sete) e 10 (dez) anos. No intervalo entre o (zero) até 13 (treze) anos - período de existência do programa, concentram-se 88,68\% das agroindústrias familiares, demonstrando que a maioria das agroindústrias iniciaram as atividades ou mesmo formalizaram-se a partir da implementação do programa, como também consolidaram-se pela participação no PFA.

Quanto à localização da propriedade, 92,45\% dos beneficiários afirmaram que suas propriedades se localizam na área rural e $88,68 \%$ deles residem na própria propriedade.

Em relação ao tamanho das propriedades, 43,40\% situam-se entre 6 e 25 ha, sendo que 90,57\% dos estabelecimentos estão enquadrados em até 4 (quatro) módulos fiscais ${ }^{2}$, limite do tamanho permitido para a classificação como pequena propriedade e para a caracterização como estabelecimento rural da agricultura familiar, segundo a classificação da Organização das Nações Unidas para Alimentação e Agricultura-FAO (2010). Em relação ao tamanho da propriedade, 9,43\% dos estabelecimentos estão desenquadrados como agricultores familiares por ultrapassarem o limite de área máxima de até quatro módulos fiscais, mesmo assim permanecendo para o programa como oriundos da agricultura familiar, caracterizando a necessidade de reenquadramento dos produtores para os critérios de participação na política segundo o tipo de produtor.

Dentre estas agroindústrias participantes do estudo, 92,45\% dos empreendimentos são explorados pelos agricultores na condição de proprietários das terras e 7,55\% estão classificados em outros tipos de exploração.

O fator trabalho nos estabelecimentos familiares abordados no estudo foi subdividido em trabalhadores permanentes e temporários, sendo a incidência destas subdivisões relacionada aos tipos de lavouras cultivadas, além de outros fatores, como a quantidade de pessoas do grupo familiar e o tamanho da área do estabelecimento. Os trabalhadores permanentes do gênero feminino
2 A medida do módulo fiscal em hectares é estabelecida

municipalmente, no Estado do Paraná a média para quatro módulos fiscais está em 72 (setenta e dois) hectares. Neste estudo foi estabelecido o intervalo para a pesquisa de campo entre 26 (vinte e seis) e 75 (setenta e cinco) hectares. Disponível em: <http://sistemafaep.org.b r/noticia. aspx?id=1397>. Acesso em: 10 mar. 2013. 
compreendem $56,25 \%$, já os trabalhadores permanentes do gênero masculino são $43,75 \%$ do total de pessoas ocupadas, em ambos os casos caracterizados como pertencentes ao grupo familiar, exercendo atividades na agroindústria.

Entre os empregados contratados, há um maior percentual de trabalhadores homens entre aqueles que são permanentes no empreendimento e uma significativa maioria de mulheres, aproximadamente $67 \%$ entre as empregadas contratadas em regime de trabalho temporário nas agroindústrias familiares. São gerados, no segmento familiar de trabalhadores permanentes, o total de 3 (três) ocupações familiares por agroindústria.

Dentre os aspectos produtivos, as agroindústrias familiares apresentaram um significativo resultado na agroindustrialização de produtos de origem vegetal, respondendo por $73,68 \%$, seguido pela panificação com $14,04 \%$ e pelos produtos de origem animal com 12,28\%. Dentre as agroindústrias, 79,2\% delas apontaram como existentes em seus produtos o registro sanitário da Agência Nacional de Vigilância Sanitária-ANVISA, que é a dispensa de registro dos produtos de origem vegetal de acordo com a resolução já citada. Já 11,3\% detém o registro sanitário do Sistema de Inspeção do Paraná/Produtos de Origem Animal-SIP/POA.

Entre as agroindústrias familiares participantes do estudo, os produtos mais comercializados são compotas de doces de frutas e legumes em conservas, como também há grande incidência de panificados e molhos.

Quanto à variabilidade de tipos de produtos oferecidos, $73,58 \%$ dos produtores comercializam pelo menos dois tipos e, no valor máximo aferido de até cinco tipos de produtos comercializados, está um estrato de 5,66\% das agroindústrias familiares.

No aspecto de comercialização dos produtos dos beneficiários do PFA, os resultados mais expressivos demonstraram que 30\% das agroindústrias familiares comercializam os produtos em âmbito regional, nos municípios próximos, $26 \%$ estadual e $16 \%$ comercializam na localidade onde a agroindústria está situada. Do mesmo modo, $28 \%$ dos beneficiários já comercializam seus produtos para outros estados brasileiros.

A Tabela 3 apresenta a distribuição dos principais pontos de comercialização dos produtos das agroindústrias familiares.

Tabela 3. Distribuição de frequência dos locais de comercialização dos produtos agroindustrializados

\begin{tabular}{lcc}
\multicolumn{1}{c}{ Locais de Comercialização } & Frequência & $\%$ \\
\hline Próprio Estabelecimento & 29 & $18,71 \%$ \\
Feira Pública & 31 & $20,00 \%$ \\
Sacolão & 9 & $5,81 \%$ \\
Supermercado & 29 & $18,71 \%$ \\
Mercado Institucional & 12 & $7,74 \%$ \\
Açougue/Padaria & 30 & $19,35 \%$ \\
Outros & 15 & $9,68 \%$ \\
TOTAL & 155 & $100,00 \%$ \\
\hline
\end{tabular}

Fonte: Autoria própria.

Nota: Esta questão admite mais de uma resposta. 
A comercialização nas grandes redes de supermercados ainda não está consolidada entre os produtores. Dentre os entrevistados, 33,96\% comercializam nas grandes redes varejistas de supermercados, significando que 66,04\% não possuem os produtos presentes nesses pontos de vendas. As justificativas relatadas entre os produtores que não comercializam os produtos nas grandes redes de supermercados referem-se, principalmente, às dificuldades de inserção das agroindústrias neste nicho de mercado e ao preço baixo em que o produto é vendido nas grandes redes. Além disso, muitos produtores acreditam que os grandes supermercados não se enquadram no seu perfil de interesse de ponto de venda. Também se destaca o principal item apontado pelos entrevistados que é a relativa capacidade de produção das agroindústrias, evidenciando as dificuldades de obtenção de escala produtiva para o fornecimento de produtos para esses supermercados.

A maior concentração de agroindústrias situa-se no estrato de volume mensal de produção de 501 (quinhentos e um) Kg ou litros, até 2.000 (dois mil) Kg ou litros, correspondendo a 35,85\% dos estabelecimentos. No estrato de estabelecimentos que produzem até 2.000 (dois mil) $\mathrm{Kg}$ ou litros estão $64,15 \%$ das agroindústrias. Cabe destacar que 5,66\% dos estabelecimentos produzem mais do que 10.000 (dez mil) Kg ou litros mensalmente, sendo uma produção significativa para a agroindustrialização de pequeno porte característica da agricultura familiar. Em 5,66\% das agroindústrias, os produtores não souberam informar qual o volume mensal de produção dos seus estabelecimentos, demonstrando a inexistência de um controle gerencial do volume produzido.

Em 28,30\% das agroindústrias, a principal matéria-prima utilizada nos processos de agroindustrialização é totalmente própria e, em 45,28\% das agroindústrias, é até $70 \%$ própria. Apenas uma das agroindústrias familiares do estudo apontou que a origem da principal matéria-prima do processo produtivo é totalmente terceirizada.

\subsection{Percepção dos beneficiários do Programa}

A avaliação dos resultados decorrentes da implementação do PFA, em comparação aos objetivos propostos pelo programa, compreende a etapa de análise da percepção dos beneficiários da política.

Grande parte dos agricultores familiares (58,49\%) obtiveram o primeiro contato com o programa por uma visita de um extensionista da Emater/PR, que identificou as potencialidades do estabelecimento para a participação em um programa de verticalização da produção como o PFA. O apontamento da grande maioria dos beneficiários para a visita de um extensionista como o ponto de partida para o ingresso no programa está de acordo com o estabelecimento institucional de atendimento da demanda do PFA. No nível de execução da política a entrada de demandas do programa é o atendimento realizado por meio da Emater/PR municipal. Nessa etapa, consiste a identificação da ideia ou proposta do agricultor e a sua viabilidade em transformar-se em um projeto de implementação de uma agroindústria ou a formalização de um empreendimento já existente. Na sequência, 
Décio Estevão do Nascimento, Caio Cesar Zerbato, Christian Luiz da Silva, Marta Chaves Vasconcelos

a proposta de ingresso deve ser analisada em nível regional e estadual (SECRETARIA..., 1999).

Uma parcela significativa de $7,55 \%$ obtiveram o primeiro contato com o programa na realização de cursos (Emater/PR, Senar/PR, Sebrae/PR). Apenas em $3,77 \%$, foi por meio de alguma entidade (Prefeitura, Sindicato, Associação, Cooperativa, outra). Tal fato evidencia a necessidade de maior articulação do programa com essas entidades locais para a prospecção de agricultores que possuem o perfil para a participação na política. Outros $3,77 \%$, por meio de outro participante. Os demais informaram que obtiveram conhecimento de outra forma.

Dentre os participantes do estudo, duas agroindústrias estão há 13 (treze) anos no programa, sendo as mais antigas apuradas na pesquisa. A média de tempo do universo de entrevistados situou-se em aproximadamente 6 (seis) anos de participação.

Em relação ao tempo de participação no programa, a maior quantidade de agroindústrias está nos estratos iniciais e intermediários de tempo de ingresso. O elevado tempo de permanência dos produtores vinculados ao programa demonstra, em certo aspecto, que o produtor ainda necessita deste vínculo com a política pública, não havendo uma plena viabilidade do empreendimento em livre concorrência com as forças de mercado.

Para o eixo do programa que tem como objetivo o fomento à inovação tecnológica nas agroindústrias familiares, foram abordadas as ações do programa voltadas para a verticalização da produção, beneficiamento da matéria-prima, produtividade e qualidade dos produtos. O nível de incremento tecnológico no processo produtivo foi aferido pelo número de equipamentos utilizados nos processos de agroindustrialização. Nesse aspecto, em 39,62\% dos estabelecimentos são utilizados até 3 equipamentos. De 4 a 6 equipamentos, representam um percentual de 24,53\%, já de 7 a 10, são $20,75 \%$. Apenas 9,43\% das agroindústrias utilizam mais de 10 equipamentos no processo produtivo e $5,66 \%$ não souberam informar quantos são utilizados. A pequena quantidade de equipamentos utilizados na produção é relacionado aos tipos de produtos mais produzidos, como compotas e conservas, que são caracteristicamente oriundos das agroindústrias de um processo de produção típico e artesanal.

Em relação aos processos de beneficiamento e transformação da matéria-prima, em $66,04 \%$ das agroindústrias estes processos eram realizados no estabelecimento antes do ingresso no programa, mas ainda não se constituíam como a principal fonte de renda da família. Em 18,87\% dos estabelecimentos, a agroindustrialização já era a principal fonte de renda. No entanto, já para 15,09\% das unidades não havia agroindustrialização nos estabelecimentos rurais. Nessa conjuntura, a política possibilitou para a maior parte dos beneficiários que a verticalização da produção e aquele considerado como o segundo ganho dos agricultores passasse a ser a principal fonte de renda da família. Em outros casos, a agroindustrialização passou a ser realizada pelo ingresso no programa com a formalização e regularização de uma unidade agroindustrial, permitindo a constituição de um empreendimento viável em regime de economia familiar. 
Em 79,25\% dos estabelecimentos, as ações do PFA foram desenvolvidas na orientação especializada ou apoio para implantação, modernização ou adequação das agroindústrias. Já na inovação tecnológica inerente às técnicas utilizadas no processo produtivo, apenas $54,25 \%$ dos beneficiários foram assistidos. Tal fato é explicado pela grande quantidade de estabelecimentos rurais que necessitavam de algum tipo de regularização ou adequação para os processos de agroindustrialização e, principalmente, para o atendimento dos procedimentos necessários higiênico-sanitários. No processo produtivo, a penetração das ações do PFA são menores, em virtude desses processos de fabricação serem considerados pelos agricultores como tradicionais, típicos ou artesanais. É neste sentido que foi apresentado um índice elevado de $20,75 \%$ dos entrevistados que afirmaram que não houve necessidade de orientação do programa para a inovação tecnológica na linha produtiva.

Nesse objetivo de promoção da inovação tecnológica, o programa apresentou um nível alto de aderência dos resultados aos objetivos propostos. Existe ainda um incipiente nível de equipamentos utilizados nos processos produtivos, mas as orientações ou apoio para implantação, modernização ou adequação dos estabelecimentos atingiram 79,25\% das agroindústrias, como também, as ações voltadas para a inovação tecnológica nos processos produtivos foram desenvolvidas em $59,25 \%$ dos estabelecimentos.

Para Mior (2005), a reprodução social dos agricultores familiares depende da ampliação das políticas públicas para o estímulo de comercialização via associativismo. As ações do programa nesse sentido estão na realização das feiras "Sabores do Paraná", em que a exposição de produtos de diversas agroindústrias distribuídas pelo estado paranaense assegura uma grande penetração no mercado para a comercialização e permite a identificação dos consumidores com as marcas e com o programa.

Em 62,26\% das agroindústrias, o PFA atuou de forma a promover orientação especializada ou apoio para a identificação de estratégias de comercialização dos produtos. O programa possui um trabalho significativo no objetivo de integração dos agricultores ao mercado com a realização das feiras "Sabores do Paraná", que proporcionam o contato do produtor rural com o cliente final. A exposição dos produtos nas feiras permite vendas para clientes corporativos e a fixação da marca para o público em geral. Em complemento à realização das feiras, o PFA possui um convênio com a APRAS para a colocação de gôndolas com os produtos das agroindústrias nas grandes redes de supermercados.

As ações do programa voltadas para a adequação e padronização de embalagens, rótulos ou layout de logomarcas atingiram 73,58\% das agroindústrias familiares. O programa implementou, em fevereiro do ano 2000, um selo que identifica os produtos provenientes das agroindústrias familiares participantes do PFA. No entanto, apenas $26,42 \%$ dos beneficiários estampam o selo do programa nos seus produtos. Já em 73,58\% dos casos o selo do PFA não está identificando os produtos, sendo que desse estrato de produtores, que não possuem o selo do PFA, 10,26\% deles possuem o Selo da Identificação da Participação na Agricultura Familiar-SIPAF do Ministério do Desenvolvimento Agrário-MDA. 
Na sequência de ações, está a orientação especializada para constituição ou regularização da unidade ou dos produtos. Em 62,26\% das agroindústrias o programa forneceu esse tipo de serviço e 15,09\% dos produtores afirmaram que nunca necessitaram da utilização desse apoio. Esse percentual de beneficiários que foram assistidos por esses serviços é reflexo de uma das mais importantes e iniciais ações do programa para os agricultores, a constituição do "Kit-Agilidade". A implementação do "Kit-Agilidade" permitiu que todos os órgãos governamentais das esferas federais, estaduais e municipais, denominados entidades participantes do programa, realizassem ações coordenadas e em menor tempo possível para a regularização e legalização das agroindústrias ou dos seus produtos nos aspectos ambientais, sanitários, jurídicos e fiscais, assegurando a disponibilização de produtos de qualidade aos consumidores (SECRETARIA..., 1999).

Em relação ao destino dos resíduos oriundos do processo produtivo, 50\% deles são destinados aos processos de compostagem, 24,19\% são utilizados como ração para animais das propriedades, 24,19\% para a coleta pública e apenas 1,61\% é queimado.

No âmbito da comercialização e da sustentabilidade, torna-se necessário a avaliação do melhor modelo de embalagem para o acondicionamento de cada produto, sendo as ações deste item do programa realizadas quase na totalidade pelas entidades parceiras, como o Sebrae/PR. Entre os participantes do estudo, os valores mais expressivos, apontam que $47,14 \%$ das embalagens utilizadas são de vidro, $35,71 \%$ delas são material plástico, $10 \%$, pote e $7,1 \%$ são bandejas.

Assim, conforme identificado, dentre as agroindústrias familiares 30,19\% afirmaram que os processos utilizados incorporam na totalidade métodos de produção de típicos de sua etnia ou localidade de residência. Também 18,85\% dos beneficiários utilizam esses mesmos processos, no entanto, com incremento de novas tecnologias. Já para $50,94 \%$ das agroindústrias, o processo produtivo não incorpora nenhum aspecto cultural ou típico da localidade do estabelecimento.

As ações do programa para o objetivo de sustentabilidade não apresentaram resultados significativos e também não estão bem definidas no escopo de planejamento da política. As ações do PFA apresentaram resultados satisfatórios sobre o destino dos resíduos do processo produtivo, mas são incipientes em relação aos tipos de materiais utilizados nas embalagens dos produtos. Esse tipo de apoio e orientação especializada é fornecido praticamente na totalidade pelas entidades parceiras do programa.

Cabe destacar que 92,46\% dos agricultores que já participaram de pelo menos um curso de qualificação ou profissionalização no âmbito do PFA demonstram que o programa tem alcançado excelentes resultados neste aspecto, seja pela capilaridade em promover cursos nas diversas regiões do estado, como na integração com as entidades parceiras do programa para a promoção desses eventos. Entre os cursos mais citados pelos agricultores estão os cursos de Boas Práticas de Fabricação-BPF e de técnicas de processo de alimentos. As entidades mais lembradas pelos agricultores como promotoras de cursos foram a Emater/PR, Sebrae/PR e Senar/PR. Em 41,94\% dos casos, os agricultores receberam assistência da Emater/PR, órgão executor do programa e 26,61\% deles receberam alguma prestação de serviço do Sebrae/PR, entidade participante do PFA, 11,29\%, de 
universidades, 1,61\%, de empresas privadas, 0,81\%, de ONGs, 16,94\% apontaram outras assistências e apenas $0,81 \%$ respondeu não, pois nunca necessitou.

Sobre o conhecimento de algum outro programa governamental voltado para a agricultura familiar, $73,58 \%$ dos produtores afirmaram conhecer alguma outra política pública. Nesse estrato de agricultores que afirmaram conhecerem outras políticas públicas para a agricultura familiar, 40,85\% dos programas citados referemse ao Pronaf, em suas diversas linhas de crédito. Demais políticas públicas também foram lembradas pelos agricultores familiares, como o Programa de Aquisição de Alimentos-PAA, que foi citado por $26,76 \%$ dos entrevistados, e o Programa Nacional de Alimentação Escolar-PNAE com 19,72\%. Já o programa paranaense Trator Solidário foi lembrado por 5,63\% dos agricultores familiares.

Desde o ingresso no programa, 50,94\% das agroindústrias familiares acessaram algum tipo de linha de crédito rural. No entanto, 24,53\% dos estabelecimentos nunca acessaram tais financiamentos e, em $24,53 \%$ dos casos, afirmaram que nunca acessaram nenhum tipo de empréstimo, pois não houve interesse em obtê-lo. Dentre os agricultores que acessaram linhas de crédito no âmbito do PFA, em 100\% dos casos foram acessadas linhas creditícias do Pronaf, destacando-se o Pronaf Agroindústria e o Pronaf Investimento.

Em 53\% das agroindústrias familiares os agricultores puderam afirmar que realmente existem perspectivas de sucessão nos negócios da família. Para $26 \%$, ainda não é possível afirmar e em $21 \%$ dos casos já é possível a afirmação de que não existem possibilidades de realização de processo sucessório na agricultura familiar. Tal informação permite avaliar que nesses casos a continuidade de parte significativa dos empreendimentos está ameaçada, sendo que poderá ocorrer uma mudança de regime de economia familiar para a agricultura empresarial ou a descontinuidade das agroindústrias em certo momento do tempo. As perspectivas de processo sucessório na agricultura familiar envolvem diversas variáveis, como as condições de infraestrutura, cidadania e renda no meio rural.

A principal fonte de renda de $58,49 \%$ das agroindústrias familiares beneficiárias do PFA é proveniente das próprias atividades agroindustriais relacionadas ao escopo da política pública. Nesse ponto, a participação das agroindústrias no programa alterou de modo sustentável a geração de renda no estabelecimento. Tal constatação é possível na medida em que os agricultores afirmaram que, antes do ingresso na política, 66,04\% dos estabelecimentos já realizavam processos de agroindustrialização, mas tais processos não eram a principal fonte de renda da família.

O nível de satisfação dos beneficiários em relação à melhoria de renda e qualidade de vida a partir do ingresso no programa apresentou altos índices de satisfação dos produtores. Os índices de satisfação nos níveis de muito satisfeito e satisfeito concentraram $94,33 \%$ das respostas, evidenciando, a partir da visão de uma parcela significativa dos beneficiários, que o ingresso no programa permitiu melhorias substancias na realidade das agroindústrias familiares. No entanto, para os agricultores existem muitos pontos em que o programa pode avançar, alcançando maiores níveis de excelência. 
Para os produtores, o PFA necessita que a Emater/PR, entidade executora do programa e responsável pelas principais ações, tanto no âmbito da extensão rural "porteira para dentro" como nas demais ações de implementação, adequação, regularização e comercialização dos produtos das agroindústrias, detenha um maior corpo técnico para o atendimento das demandas. Atualmente, o programa dispõe de 28 (vinte e oito) executores regionais da Emater/PR para o atendimento de todas as agroindústrias cadastradas no programa (SECRETARIA..., 2010). Além disso, não há a disponibilidade exclusiva dos técnicos apenas para o atendimento do PFA, sendo os profissionais requisitados também por outros agricultores clientes da Emater/PR. A deficiência do número de profissionais do corpo da instituição distribuídos nos municípios paranaenses é apontada pelos agricultores para o segmento "porteira para dentro". Eles sentem a ausência de um maior nível de atendimento na orientação especializada dos processos produtivos realizados no campo.

Os agricultores também apontaram a necessidade de formalização e normatização de mais parcerias com instituições que possam apoiar a agricultura familiar e agroindústria no Estado do Paraná. As parcerias com instituições públicas de pesquisa, como as universidades, já foram maiores no âmbito do programa e hoje praticamente inexistem para os agricultores. O foco na comercialização é o principal item para os agricultores familiares, principalmente para aqueles que já possuem certo de tempo de participação na política e possuem o empreendimento consolidado.

O Quadro 4 sintetiza os resultados do programa em relação aos objetivos propostos pela política, segundo a visão dos beneficiários.

Quadro 4. Aderência dos resultados aos objetivos do PFA, segundo a percepção dos beneficiários do programa

\begin{tabular}{|c|c|c|}
\hline Objetivo & $\begin{array}{c}\text { Aderência dos } \\
\text { resultados aos } \\
\text { objetivos do } \\
\text { programa }\end{array}$ & Justificativa \\
\hline $\begin{array}{l}\text { Inovação } \\
\text { tecnológica }\end{array}$ & Alta & $\begin{array}{l}\text { As ações de inovação tecnológica voltadas para as unidades rurais atingiram } \\
79,25 \% \text { das agroindústrias e para os processos produtivos } 54,72 \% \text {; em } 66 \% \text { dos } \\
\text { estabelecimentos os processos de agroindustrialização já eram realizados, mas } \\
\text { ainda não se constituíam antes do programa como a principal fonte de renda da } \\
\text { família. No entanto, ainda existe uma limitada quantidade de equipamentos } \\
\text { utilizados nos processos produtivos, pois grande parte da produção das } \\
\text { agroindústrias é realizada de forma artesanal, sendo que apenas } 9,43 \% \text { das } \\
\text { unidades rurais utilizam mais de } 10 \text { (dez) equipamentos. }\end{array}$ \\
\hline Foco no mercado & Alta & $\begin{array}{l}\text { As Ações voltadas para as estratégias de comercialização atingiram } 62,26 \% \text { das } \\
\text { agroindústrias e para a melhoria dos produtos } 73,58 \% ; 58 \% \text { das agroindústrias } \\
\text { familiares comercializam os produtos em âmbito regional (municípios } \\
\text { próximos) e para outros estados brasileiros. Em } 33,96 \% \text { das agroindústrias os } \\
\text { produtos são comercializados nas grandes redes varejistas de supermercados, } \\
\text { considerado um elevado percentual para a agricultura familiar, principalmente, } \\
\text { pela fato de que os produtores que não comercializam não expressaram } \\
\text { interesse nesse nicho de mercado. O selo de identificação do programa ainda é } \\
\text { pouco utilizado, aparecendo nos produtos de } 26,42 \% \text { dos estabelecimentos. }\end{array}$ \\
\hline Sustentabilidade & Baixa & $\begin{array}{l}\text { O destino dos resíduos do processo produtivo é em apenas } 50 \% \text { dos casos } \\
\text { destinado a compostagem e em } 24,19 \% \text { utilizado como ração para os animais; os } \\
\text { principais tipos de embalagem utilizadas são em } 47,14 \% \text { de vidro e, em } 35,71 \% \text {, de } \\
\text { saco plástico. Para as agroindústrias participantes, somente em } 30,19 \% \text { os } \\
\text { processos produtivos incorporam métodos de produção típicos de etnia ou da } \\
\text { localidade de residência. }\end{array}$ \\
\hline
\end{tabular}


Política pública para a agricultura familiar: avaliação do Programa Paranaense "Fábrica do Agricultor"

(conclusão)

\begin{tabular}{|c|c|l|}
\hline Objetivo & $\begin{array}{c}\text { Aderência dos } \\
\text { resultados aos } \\
\text { objetivos do } \\
\text { programa }\end{array}$ & Justificativa \\
\hline $\begin{array}{c}\text { Integração com } \\
\text { as entidades }\end{array}$ & Média & $\begin{array}{l}\text { No âmbito do programa em 50,94\% das agroindústrias familiares houve o } \\
\text { acesso a alguma linha de crédito rural. Em relação às políticas públicas para o } \\
\text { segmento, 73,58\% dos produtores afirmaram conhecer alguma outra política } \\
\text { pública para a agricultura familiar. No entanto, na assistência técnica ou } \\
\text { extensão, dentre os beneficiados, apenas 41,94\% dos agricultores receberam } \\
\text { assistência da Emater/PR, órgão executor do programa e 26,61\% deles } \\
\text { receberam alguma prestação de serviço do Sebrae/PR, entidade participante do } \\
\text { PFA. }\end{array}$ \\
\hline $\begin{array}{c}\text { Desenvolvimento } \\
\text { regional }\end{array}$ & $\begin{array}{l}\text { As } 53 \text { agroindústrias geram 200 empregos permanentes e 41 temporários. Os } \\
\text { trabalhadores permanentes do gênero feminino compreendem 56,25\%, já os } \\
\text { trabalhadores permanentes do gênero masculino são 43,75\%. A principal fonte } \\
\text { de renda de 58,49\% das agroindústrias familiares beneficiárias do PFA é } \\
\text { proveniente das próprias atividades agroindustriais relacionadas ao escopo da } \\
\text { política pública. No aspecto de acesso às políticas públicas para a agricultura } \\
\text { familiar, 52,83\% das agroindústrias participantes afirmaram que já acessaram } \\
\text { algum tipo de programa governamental para o segmento. }\end{array}$ \\
\hline $\begin{array}{c}\text { Apoio à } \\
\text { agricultura } \\
\text { familiar }\end{array}$ & $\begin{array}{l}\text { No âmbito das ações de apoio à agricultura familiar, em 100\% dos casos, a } \\
\text { gestão dos estabelecimentos é realizada apenas por membros do núcleo } \\
\text { familiar e são 92,46\% dos agricultores que já participaram de pelo menos um } \\
\text { curso de qualificação ou profissionalização no âmbito do PFA. Sobres as } \\
\text { perspectivas de perpetuidade do empreendimento familiar, em 53\% das } \\
\text { agroindústrias familiares os agricultores já puderam afirmar que existe } \\
\text { perspectiva de processo sucessório no empreendimento. }\end{array}$ \\
\hline Alta
\end{tabular}

Fonte: Autoria Própria.

A partir da percepção dos beneficiários da política pública sobre os resultados alcançados decorrentes da implementação do programa e comparandoos aos objetivos propostos, cabe identificar do mesmo modo a visão dos policymakers e das entidades participantes.

\subsection{Percepção dos policy-makers e das entidades participantes}

A percepção dos policy-makers e das entidades participantes referem-se à visão desses agentes sobre os resultados alcançados pelo programa decorrentes da sua implementação. O Quadro 5 sintetiza a descrição do perfil dos participantes do estudo. 
Décio Estevão do Nascimento, Caio Cesar Zerbato, Christian Luiz da Silva, Marta Chaves Vasconcelos

Quadro 5. Formação, cargo, nível de atuação e perfil profissional dos entrevistados policy-makers e das entidades participantes do PFA

\begin{tabular}{|c|c|l|}
\hline Entrevistado & $\begin{array}{c}\text { Formação/Cargo/Nível de } \\
\text { atuação }\end{array}$ & \multicolumn{1}{c|}{ Perfil Profissional } \\
\hline PM1 & $\begin{array}{c}\text { Engenheiro Agrônomo, } \\
\text { atuação na área gerencial }\end{array}$ & $\begin{array}{l}\text { Experiência de } 38 \text { (trinta e oito) anos na Emater/PR, } \\
\text { participante do grupo que elaborou a proposta do } \\
\text { PFA, atuou durante 4 (quatro) anos como gerente } \\
\text { administrativo da entidade, retornando após este } \\
\text { período para a equipe de coordenação da política. }\end{array}$ \\
\hline PM2 & $\begin{array}{c}\text { Engenheiro Agrônomo, } \\
\text { atuação na área gerencial }\end{array}$ & $\begin{array}{l}\text { Experiência de 37 (trinta e sete) anos na Emater/PR, } \\
\text { participante do grupo que elaborou a proposta do } \\
\text { PFA, atuou desde então nos últimos 14 (quatorze) } \\
\text { anos na equipe de coordenação da política. }\end{array}$ \\
\hline EP1 & $\begin{array}{c}\text { Engenharia Química, atuação } \\
\text { em nível gerencial }\end{array}$ & $\begin{array}{l}\text { Experiência de 4 (quatro) anos na área de } \\
\text { agronegócio em função estratégica e de 3 (três) } \\
\text { anos na área de inovação tecnológica para } \\
\text { agroindústrias. }\end{array}$ \\
\hline EP2 & $\begin{array}{c}\text { Administração de Empresas } \\
\text { com MBA em } \\
\text { empreendedorismo, atuação } \\
\text { em nível consultivo }\end{array}$ & $\begin{array}{l}\text { Experiência de 23 (vinte e três) anos na entidade } \\
\text { participante, com atuação na área de gestão de } \\
\text { projetos da cadeia de hortifruti. }\end{array}$ \\
\hline $\begin{array}{c}\text { Profissional de Nível Superior, } \\
\text { atuação em nível analítico }\end{array}$ & $\begin{array}{l}\text { Experiência de 7 (sete) anos em reforma agrária e } \\
\text { desenvolvimento rural. }\end{array}$ \\
\hline
\end{tabular}

Fonte: Autoria Própria.

A percepção desses agentes sobre os resultados do programa abordam a integração com as entidades participantes e os resultados decorrentes da implementação da política. As ações de integração do programa com as demais entidades são realizadas após o atendimento inicial da demanda e a verificação das necessidades das agroindústria descrita na proposta de ingresso no PFA. A partir da identificação da demanda, sendo ela por inovação e pesquisa, existe o encaminhamento e conta com universidades da região que possam atender aos agricultores. No aspecto da capacitação e profissionalização dos agricultores, ao ser identificada esta necessidade nas localidades, as unidades regionais da Emater/PR ficam responsáveis pela elaboração de uma agenda de compromissos para a participação dos beneficiários nos cursos. As entidades parceiras que mais promovem esses cursos são o Sebrae/PR e o Senar/PR, que inclusive enviam as agendas de datas anuais de realização de cursos e eventos voltados para o público alvo do programa (ENTREVISTADO PM1; ENTREVISTADO PM2).

Além disso, a integração com as entidades participantes dos beneficiários do PFA é realizada pelo interesse das próprias entidades na prospecção de novas demandas dos agricultores. Os trabalhos são realizados nas feiras "Sabores do Paraná" onde existe um contato da entidade com os produtores e são apresentados os produtos e serviços oferecidos, como projetos de rótulos, embalagens, layout de logomarcas e oferecimento de cursos de capacitação e profissionalização. Para o Entrevistado EP1, existe a prospecção de agroindústrias nas regiões de Centro-Sul e Noroeste Paranaense, com o objetivo de sensibilização da melhoria da qualidade e segurança dos alimentos. 
O atendimento das agroindústrias é realizado pelas entidades participantes, em muitos casos, por solicitação da prefeitura do município ou de alguma associação ou sindicato tendo agroindústrias vinculadas ao programa (ENTREVISTADO EP2). Já para o Entrevistado PM2 o atendimento do extensionista da Emater/PR na propriedade identificada todas as demandas necessárias para a participação da agroindústria e, caso seja necessário o encaminhamento para a assistência de alguma entidade participante, este procedimento é realizado.

A integração com as entidades participantes apresenta excelentes resultados para esses parceiros do programa. Para o Entrevistado EP1, a participação de sua entidade como parceira do programa fortalece a marca e consolida o trabalho com os pequenos empreendimentos agroindustriais. Atuando conjuntamente com o PFA, é possível realizar um trabalho que a entidade sozinha não teria como realizar, com a abrangência do estado paranaense.

Além da avaliação da integração com as entidades, cabe aos policy-makers e às entidades participantes do PFA identificarem os resultados alcançados decorrentes da implementação do programa. De acordo com a percepção das entidades participantes, o que se pretendeu atingir com a implementação do programa foi o desenvolvimento de novos produtos, regularização das agroindústrias e capacitação dos produtores. Existem, pelas entidades, metas a serem alcançadas para a melhoria das estratégias de marketing e dos processos de comercialização dos produtos. Como também aperfeiçoamento na composição dos produtos, atendendo às necessidades dos consumidores, como produtos com menos sódio e açúcar (ENTREVISTADO EP1; ENTREVISTADO EP3).

Segundo o Entrevistado EP2, os resultados decorrentes da implementação do PFA são as facilidades com que o produtor pode obter a regularização ou adequação dos produtos às normas vigentes, pelo apoio e as ações coordenadas desenvolvidas pelo programa para as agroindústrias.

Ainda para as entidades participantes, os resultados que não eram esperados do programa foram a realização de consultorias in loco nas agroindústrias e o relevante benefício social do programa para os agricultores e para a sociedade em geral, com o alcance de novos mercados e o desenvolvimento das agroindústrias familiares em todo o Estado do Paraná, visibilidade que seria dificilmente alcançada pelos agricultores individualmente sem o apoio institucional que é oferecido pelo programa (ENTREVISTADO EP2). Para o Entrevistado EP1, os parceiros também identificaram oportunidades e desafios para a política, sendo primordialmente relatada a necessidade de encontros regionais entre os técnicos executores do programa e as entidades parceiras para que seja traçado um planejamento estratégico alinhado às especificidades locais das agroindústrias, caracterizando como o grande desafio da política ampliar as parcerias.

Em relação ao nível de satisfação das entidades parceiras, foi apontada a grande satisfação em participar do programa e os efeitos benéficos para a entidade em ser parceira da política. Para o Entrevistado EP1, ainda existem muitos desafios e muita sinergia necessária para o estabelecimento de uma relação mais produtiva para ambas as partes e que a entidade participante não seja vista como concorrente da Emater/PR, mas sim uma parceira de trabalho, maximizando os resultados da política. 
$\mathrm{Na}$ percepção dos policy-makers o que se pretendeu atingir com a implementação da política foi a consolidação das agroindústrias que existiam e integrar os demais agricultores em uma proposta de agregação de renda e geração de valor (ENTREVISTADO PM1). Já para o Entrevistado PM2, na implementação do programa, não havia o zelo com a agricultura familiar, mas, sim, com o objetivo de agroindustrializar.

Em relação aos recursos atuais de que dispõe o programa, existem grandes necessidades de recursos humanos, estruturais e financeiros para o atendimento das demandas que surgem no PFA. Segundo o Entrevistado PM2, é necessário promover uma atualização de todo o portfólio do programa para a promoção de um bom nível de atendimento aos agricultores.

Para os policy-makers, o programa está atingindo os resultados a que se propõe, com as estratégias de agroindustrialização para a manutenção da família rural no campo.

Os resultados que o programa apresenta ao longo da sua história são diferenciados entre as regiões paranaenses, até mesmo pela tradição em certas localidades de famílias tradicionais de agricultores ou os chamados colonos. Segundo o Entrevistado PM1, as localidades em que o PFA apresenta os melhores resultados compreendem a região de Cascavel e os municípios limítrofes, Londrina e Maringá. No entanto, as regiões onde as ações do programa estão mais deficientes são as de Pato Branco e Ivaiporã (ENTREVISTADO PM1). Segundo o Entrevistado PM2, os melhores resultados do PFA estão na Região Metropolitana de Curitiba, no Litoral Paranaense, Cascavel e Francisco Beltrão. Como também apresentam resultados intermediários, os municípios de Cornélio Procópio, Santo Antonio da Platina, Maringá, Londrina, Pato Branco, Ponta Grossa, Toledo e Campo Mourão. Além disso, destacam-se os relevantes resultados das agroindústrias nas vendas para a Secretaria Municipal de Abastecimento de Curitiba, no projeto Armazém da Família, que é o principal cliente institucional dos beneficiários do PFA.

O programa possui mecanismos de avaliação e correção da política com a realização de pesquisas de satisfação com os agricultores durante a realização dos eventos e a própria mudança de direcionamento do programa para o foco no público da agricultura familiar demonstrou esta intenção em promover melhorias contínuas.

Os desafios e oportunidades que o PFA tem são determinantes para o futuro da política e a sua relação com os agricultores e as mudanças na sociedade. Para o Entrevistado PM1, em um primeiro ponto, é necessário ampliar o quadro técnico da Emater/PR com técnicos especializados em processamento de alimentos e técnicas de agroindustrialização. Além disso, a disponibilização de mais recursos estruturais e financeiros para o atendimento das demandas em todo o estado paranaense, inclusive com a promoção de mais eventos do programa.

Os resultados apresentados pelo programa na visão dos policy-makers e das entidades participantes evidenciam as transformações da política em convergência com a mudança de paradigma sobre a agricultura familiar e seu papel como indutora de desenvolvimento rural. 
Política pública para a agricultura familiar: avaliação do Programa Paranaense “Fábrica do Agricultor"

\section{Considerações finais}

A matriz fundiária do estado paranaense possui mais de 300 (trezentos) mil estabelecimentos rurais da agricultura familiar, o que representa mais de $81 \%$ de todos os estabelecimentos agrícolas do estado. Além disso, a agricultura familiar responde por mais de $69 \%$ do pessoal ocupado e $43 \%$ do valor bruto da produção agropecuária paranaense.

A partir da relevância da agricultura familiar para o Estado do Paraná, em 1999 foi criado uma política pública voltada para o fortalecimento desse modo de produção com o intuito de promover a agregação de valor, geração de renda e emprego. Surge o PFA, com o intuito de promover a agroindustrialização dos produtos nos estabelecimentos rurais, verticalizando a produção e viabilizando os estabelecimentos rurais familiares.

A partir dessa conjuntura, este artigo teve como objetivo principal identificar a relação entre os objetivos do PFA, a partir da percepção dos agentes envolvidos, e seus resultados. Com a realização da pesquisa de campo com 53 (cinquenta e três) agroindústrias familiares, foi possível identificar a percepção dos agricultores familiares beneficiários da política. Como também por meio de entrevistas com os policy-makers e as entidades participantes do programa, foi possível identificar conjuntamente os resultados decorrentes da implementação do programa ao longo dos anos de existência da política e compará-los, classificando-os conforme o nível de aderência desses resultados aos objetivos propostos pelo PFA.

O programa apresentou os resultados mais expressivos em suas contribuições para a regularização dos empreendimentos, foco no mercado e capacitação e profissionalização dos agricultores. A visão mercadológica do programa é o eixo mais forte de trabalho da política e a realização das feiras "Sabores do Paraná", em que os produtos das agroindústrias beneficiárias do programa são comercializados aos consumidores finais é o ponto mais importante e lembrado da política na percepção dos participantes. Para os agricultores familiares, o programa deveria ampliar a realização das feiras entre as regiões paranaenses e estabelecer uma periodicidade para os eventos. Outro ponto destacado na análise do programa é a capacitação e profissionalização dos agricultores.

O programa não apresentou resultados significativos em todos os seis objetivos estabelecidos para a política, classificando como alta aderência dos resultados os objetivos de inovação tecnológica, foco no mercado e apoio à agricultura familiar. Já os objetivos de desenvolvimento regional e integração com as entidades apresentaram resultados de média aderência aos objetivos propostos. Do mesmo modo, o objetivo de sustentabilidade apresentou baixa aderência dos resultados aos objetivos da política, na medida em que não foi possível identificar ações específicas e consolidadas no escopo do programa para a consecução do planejamento. Além da identificação dos resultados do programa em relação aos seus objetivos, a avaliação do nível de satisfação dos beneficiários em relação à política é extremamente alta e de grande relevância.

$\mathrm{Na}$ visão dos policy-makers e entidades participantes, o programa cumpre suas funções e apresenta um valoroso histórico de promoção do desenvolvimento da agricultura familiar no estado paranaense. Atualmente, a política necessita de expansão de recursos, tanto humanos como estruturais e financeiros, dado a 
Décio Estevão do Nascimento, Caio Cesar Zerbato, Christian Luiz da Silva, Marta Chaves Vasconcelos

magnitude e dimensão da relevância das atividades do programa para a agroindústria do estado.

Sugere-se, como estudos futuros, o dimensionamento das políticas públicas para a agricultura familiar no estado paranaense, analisando os aspectos de intersetorialidade das políticas e seus impactos, aplicando em recorte teórico de análise específica a importância do insumo tecnologia nas agroindústrias familiares.

\section{REFERÊNCIAS}

ABRAMOVAY, Ricardo. De volta para o futuro: mudanças recentes na agricultura familiar. In: SEMINÁRIO NACIONAL DO PROGRAMA DE PESQUISA EM AGRICULTURA FAMILIAR DA EMBRAPA. 1. 1997, Petrolina. Anais...Petrolina: EMBRAPA, 1997. Disponível em:

<http://issuu.com/ricardoabramovay/docs/de_volta_para_o_futuro $>$. Acesso em: 04 nov. 2012.

ALA-HARJA, Marjukka; HELGASON, Sigurdur. Em direção às melhores práticas de avaliação. Revista do Serviço Público, Brasília, v. 51, n. 4, out./dez. 2000. Disponível em:

<http://www.enap.gov.br/index.php?option=com_docman\&task=doc_view\&gid=26 75\&ltemid=129>. Acesso em: 18 nov. 2012.

BRASIL. Decreto $n^{\circ} 1.946$, de 28 de junho de 1996. Cria o Programa Nacional de Fortalecimento da Agricultura Familiar - PRONAF, e dá outras providências. Diário Oficial da União da República Federativa do Brasil, Brasília, DF, 01 jul. 1996. Disponível em:

<http://www.in.gov.br/visualiza/index.jsp?jornal=1\&pagina=2\&data=01/07/1996>.

Acesso em: 12 nov. 2012.

CHAYANOV, Alexander Von. Sobre a teoria dos sistemas econômicos não capitalistas. In: GRAZIANO DA SILVA, José; STOLCKE, Verena (Organizadores). A questão agrária. São Paulo: Editora Brasiliense, 1981.

DYE, Thomas R. Mapeamento dos modelos de análise de políticas públicas. In: HEIDEMANN, Francisco G. e SALM, José Francisco (Organizadores). Políticas públicas e desenvolvimento: bases epistemológicas e modelos de análise. Brasília: UNB, 2009.

ESSER, Jovir Vicentini. et al. As vilas rurais na região Oeste do Estado do Paraná: uma política pública de desenvolvimento e seu impacto na vida dos trabalhadores rurais volantes. Revista Paranaense de Desenvolvimento, Curitiba, n. 110, jan./jun. 2006. em: <http://www.ipardes.pr.gov.br/ojs/index.php/revistaparanaense/article/view/124/119>. Acesso em: 21 dez. 2012. 
Política pública para a agricultura familiar: avaliação do Programa Paranaense "Fábrica do Agricultor"

FREY, Klaus. Políticas públicas: um debate conceitual e reflexões referente à prática da análise de políticas públicas no Brasil. In: Planejamento e políticas públicas, Brasília, n. 21, 2000. Disponível em:

<http://desafios2.ipea.gov.br/ppp/index.php/PPP/article/viewFile/89/158>.

Acesso em: 26 ago. 2012.

GODOY, Amália M. Goldberg. Aprendizagem coletiva e avanços tecnológicos e ambientais na agricultura paranaense. Revista Paranaense de Desenvolvimento, Curitiba, n. 110, jan./jun. 2006.2 Disponível em: <http://www.ipardes.pr.gov.br/ojs/index.php/revistaparanaense/article/view/114/118>. Acesso em: 21 dez. 2012.

GOODMAN, D. E.; SORJ, Bernardo.; WILKINSON, John. Agroindústria, políticas públicas e estruturas sociais rurais: análises recentes sobre a agricultura brasileira. Revista de Economia Política, São Paulo, v. 3, n. 4, out./dez. 1985. Disponível em <http://www.bernardosorj.com.br/pdf/agroindustriapoliticaspublicaseestruturassoci aisrurais.pdf >. Acesso em: 16 out. 2012.

GRAZIANO DA SILVA, José; DEL GROSSI, Mauro Eduardo; CAMPANHOLA, Clayton. O que há de realmente novo no rural brasileiro. Cadernos de Ciência \& Tecnologia, Brasília, v. 19, n. 1, jan./abr. 2002. Disponível em: <http://www.economia.esalq.usp.br/intranet/uploadfiles/1115.pdf>. Acesso em: 09 nov. 2012.

HEIDEMANN, Francisco G. Do sonho do progresso às políticas de desenvolvimento. In: HEIDEMANN, Francisco G. e SALM, José Francisco (Organizadores). Políticas públicas e desenvolvimento: bases epistemológicas e modelos de análise. Brasília: UNB, 2009.

INSTITUTO BRASILEIRO DE GEOGRAFIA E ESTATÍSTICA. Censo Agropecuário 2006: Brasil, Grandes Regiões e Unidades da Federação. Rio de Janeiro: IBGE, 2009. Disponível em: <http://www.ibge.gov.br/home/estatistica/economia/agropecuaria/censoagro/defau It.shtm>. Acesso em: $21 \mathrm{dez} .2012$.

. Censo Agropecuário 2006: resultados preliminares. Rio de Janeiro: IBGE, 2007. Disponível em: <http://www.ibge.gov.br/home/estatistica/economia/agropecuaria/censoagro/2006/ agropecuario.pdf>. Acesso em: 28 dez. 2012.

Censo Agropecuário de 1995-1996. Rio de Janeiro: IBGE, 1996. Disponível em:

<http://www.ibge.gov.br/home/estatistica/economia/agropecuaria/censoagro/1995_ 1996/default.shtm>. Acesso em: 21 dez. 2012.

INSTITUTO PARANAENSE DE DESENVOLVIMENTO ECONÔMICO E SOCIAL. Leituras regionais: mesorregiões geográficas paranaenses: sumário executivo, IPARDES: 
Décio Estevão do Nascimento, Caio Cesar Zerbato, Christian Luiz da Silva, Marta Chaves Vasconcelos

Curitiba, 2004. Disponível em: <http://www.ipardes.gov.br/biblioteca/docs/leituras_reg_sumario_executivo.pdf>. Acesso em: 21 dez. 2012.

. Leituras regionais: mesorregião geográfica Oeste paranaense, IPARDES: Curitiba, 2004a. Disponível em: <http://www.ipardes.gov.br/biblioteca/docs/leituras_reg_meso_oeste.pdf>. Acesso em: 21 dez. 2012.

. Leituras regionais: mesorregião geográfica Sudoeste paranaense, IPARDES: Curitiba, 2004b. Disponível em: <http://www.ipardes.gov.br/biblioteca/docs/leituras_reg_meso_sudoeste.pdf>. Acesso em: 22 dez. 2012.

- Leituras regionais: mesorregião geográfica Metropolitana de Curitiba, IPARDES: Curitiba, 2004C. Disponível em: <http://www.ipardes.gov.br/biblioteca/docs/leituras_reg_meso_metropolitana_curi tiba.pdf >. Acesso em: 12 fev. 2012.

- Leituras regionais: mesorregião geográfica Norte Central paranaense, IPARDES: Curitiba, 2004d. Disponível em: <http://www.ipardes.gov.br/biblioteca/docs/leituras_reg_meso_norte_central.pdf >. Acesso em: 12 fev. 2012.

. Leituras regionais: mesorregião geográfica Norte Pioneiro paranaense, IPARDES: Curitiba, 2004e. Disponível em: <http://www.ipardes.gov.br/biblioteca/docs/leituras_reg_meso_norte_pioneiro.pdf >. Acesso em: 12 fev. 2012.

LAKATOS, Eva Maria; MARCONI, Marina de Andrade. Metodologia Científica. 5 ed. São Paulo: Atlas, 2008.

MALUF, Renato Sergio Jamil. Multifuncionalidade da agricultura familiar no Brasil e o enfoque de pesquisa. In: GAZELLA, Ademir A.; BONNAL, Philippe; MALUF, Renato S. Jamil (Organizadores). Agricultura familiar: multifuncionalidade e desenvolvimento territorial no Brasil. Rio de Janeiro: Mauad X, 2009.

MIOR, Luiz Carlos. Agricultores familiares, agroindústrias e redes de desenvolvimento rural. Chapecó: Argos, 2005.

OLIVEIRA, Ariovaldo Umbelino de. A longa marcha do campesinato brasileiro: movimentos sociais, conflitos e reforma agrária. Estud. av., São Paulo, v. 15, n. 43, dez. 2001. Disponível em: <http://www.scielo.br/scielo.php? script=sci_arttext\&pid=S0103-4 0142001000300015\&lng=pt\&nrm=iso > Acesso em: 20 mai. 2012. 
Política pública para a agricultura familiar: avaliação do Programa Paranaense "Fábrica do Agricultor"

OLIVEIRA, José Antonio Puppim de. Desafios do planejamento em políticas públicas: diferentes visões e práticas. Revista de Administração Pública, Rio de Janeiro, v. 40, n. 2, mar./abr. 2006. Disponível em: <http://www.scielo.br/scielo.php?script=sci_arttext\&pid=S00347612200600020000 6\&lng=en\&nrm=iso >. Acesso em: 18 nov. 2012.

PEREIRA, Valeria V. V. Reveles; BAZOTTI, Angelita. Ruralidade, agricultura familiar e desenvolvimento. Nota Técnica IPARDES, Curitiba, n. 16, 2010. Disponível em: <http://www.ipardes.pr.gov.br/biblioteca/docs/NT_16_ruralidade_agric_familiar_des env.pdf $>$. Acesso em: 18 nov. 2012.

SCHNEIDER, Sérgio. Teoria social, agricultura familiar e pluriatividade. Revista Brasileira de Ciências Sociais, Porto Alegre, v. 18, n. 51, 2003. Disponível em: <http://www.ufrgs.br/pgdr/arquivos/389.pdf>. Acesso em: 07 nov. 2012.

SCHNEIDER, Sérgio; CAZELLA, Ademir; MATTEI, Lauro F. Histórico, caracterização e dinâmica recente do PRONAF - Programa Nacional de Fortalecimento da Agricultura Familiar. In: SCHNEIDER, Sérgio; SILVA, Marcelo Kunrath; MARQUES, Paulo Eduardo Moruzzi (Organizadores). Políticas públicas e participação social no Brasil rural. 2 ed., Porto Alegre: Editora da UFRGS, 2009.

SECRETARIA DE ESTADO DA AGRICULTURA E DO ABASTECIMENTO DO GOVERNO DO ESTADO DO PARANÁ. Fábrica do Agricultor, Curitiba, 2011.

Agroindústria familiar "Fábrica do Agricultor" relatório de atividades especiais - 1998 a 2010, Curitiba, 2010.

. Fábrica do Agricultor, Curitiba, 1999.

SIMÃO et al. Indicadores, políticas públicas e a sustentabilidade. In: In: SILVA, Christian Luiz da e SOUZA-LIMA, José Edmilson de (Organizadores). Políticas públicas e indicadores para o desenvolvimento sustentável. São Paulo: Saraiva, 2010.

SOUZA, Celina. Políticas públicas: uma revisão de literatura. Sociologias, Porto Alegre, n. 16, dez. 2006. Disponível em: <http://www.scielo.br/scielo.php?script=sci_arttext\&pid=S151745222006000200003 \&lng=pt\&nrm=iso >. Acesso em: 15 nov. 2012.

UNIVERSIDADE Estadual de Campinas (UNICAMP). Núcleo de Estudos de Políticas Públicas (NEPP). Modelos de avaliação de programas sociais prioritários: relatório final. Campinas, 1999. 133 p. Disponível em: <http://new.paho.org/bra/index.php?option=com_docman\&task=doc_details\&gid=5 57\&ltemid=423>. Acesso em: 16 nov. 2012. 
Décio Estevão do Nascimento, Caio Cesar Zerbato, Christian Luiz da Silva, Marta Chaves Vasconcelos

WESZ JUNIOR, Valdemar João. As políticas públicas de agroindustrialização na agricultura familiar: análise e avaliação da experiência brasileira. 2009. $218 \mathrm{f}$. Dissertação (Mestrado em Ciências Sociais) - Instituto de Ciências Humanas e Sociais, Universidade Federal Rural do Rio de Janeiro, Rio de Janeiro, 2009. Disponível em: <http://bdtd.ufrrj.br/tde_busca/arquivo.php?codArquivo=1299>. Acesso em: 19 nov. 2012.

Décio Estevão do Nascimento. Professor do Programa de Pós Graduação em Planejamento e Governança Pública e do Programa de Pós Graduação em Tecnologia. Universidade tecnológica Federal do Paraná. Av: Sete de Setembro, 3165 - Rebouças - Curitiba - Paraná - Brasil - CEP: 80230-901. decioen@gmail.com

Caio Cesar Zerbato. Mestre em Planejamento e Governança Pública. Universidade tecnológica Federal do Paraná. Av: Sete de Setembro, 3165 Rebouças - Curitiba - Paraná Brasil - CEP: 80230-901. caio.zerbato@gmail.com

Christian Luiz da Silva. Professor do Programa de Pós Graduação em Planejamento e Governança Pública e do Programa de Pós Graduação em Tecnologia. Universidade tecnológica Federal do Paraná. Av: Sete de Setembro, 3165 - Rebouças - Curitiba - Paraná - Brasil - CEP: 80230-901. christianlsilva76@gmail.com

Marta Chaves Vasconcelos. Mestranda em Administração. Pontifícia Universidade Católica do Paraná. Rua: Imaculada Conceição, 1155 - Prado Velho Curitiba - Paraná - Brasil - CEP: 81611-970. martacvasconcelos@hotmail.com 